University of Wollongong

Research Online

Faculty of Engineering and Information

Faculty of Engineering and Information

Sciences - Papers: Part A

Sciences

$1-1-2014$

Sludge cycling between aerobic, anoxic and anaerobic regimes to reduce sludge production during wastewater treatment: Performance, mechanisms, and implications

Galilee Semblante

University of Wollongong,gus193@uowmail.edu.au

Faisal Ibney Hai

University of Wollongong, faisal@uow.edu.au

Huu H. Ngo

University of Technology Sydney

Wenshan Guo

University of Technology Sydney

Sheng-Jie You

Chung Yuan Christian University

See next page for additional authors

Follow this and additional works at: https://ro.uow.edu.au/eispapers

Part of the Engineering Commons, and the Science and Technology Studies Commons

Research Online is the open access institutional repository for the University of Wollongong. For further information contact the UOW Library: research-pubs@uow.edu.au 


\title{
Sludge cycling between aerobic, anoxic and anaerobic regimes to reduce sludge production during wastewater treatment: Performance, mechanisms, and implications
}

\begin{abstract}
Alternate cycling of sludge in aerobic, anoxic, and anaerobic regimes is a promising strategy that can reduce the sludge yield of conventional activated sludge (CAS) by up to $50 \%$ with potentially lower capital and operating cost than physical- and/or chemical-based sludge minimisation techniques. The mechanisms responsible for reducing sludge yield include alterations to cellular metabolism and feeding behaviour (metabolic uncoupling, feasting/fasting, and endogenous decay), biological floc destruction, and predation on bacteria by higher organisms. Though discrepancies across various studies are recognisable, it is apparent that sludge retention time, oxygen-reduction potential of the anaerobic tank, temperature, sludge return ratio and loading mode are relevant to sludge minimisation by sludge cycling approaches. The impact of sludge minimisation on CAS operation (e.g., organics and nutrient removal efficiency and sludge settleability) is highlighted, and key areas requiring further research are also identified.
\end{abstract}

\section{Keywords}

reduce, regimes, anaerobic, anoxic, aerobic, between, cycling, sludge, performance, treatment, implications, wastewater, mechanisms, during, production

Disciplines

Engineering | Science and Technology Studies

\section{Publication Details}

Semblante, G., Hai, F. Ibney., Ngo, H. H., Guo, W., You, S., Price, W. E. \& Nghiem, L. D. (2014). Sludge cycling between aerobic, anoxic and anaerobic regimes to reduce sludge production during wastewater treatment: Performance, mechanisms, and implications. Bioresource Technology, 155 (March), 395-409.

\section{Authors}

Galilee Semblante, Faisal Ibney Hai, Huu H. Ngo, Wenshan Guo, Sheng-Jie You, William Price, and Long Nghiem 


\title{
Sludge cycling between aerobic, anoxic and anaerobic regimes to reduce sludge production during wastewater treatment: performance, mechanisms, and implications
}

\author{
Revised Manuscript Submitted to \\ Bioresource Technology
}

Jan 2014

Galilee U. Semblante ${ }^{\mathrm{a}}$, Faisal I. Hai*, Huu H. Ngo ${ }^{\mathrm{b}}$, Wenshan Guo ${ }^{\mathrm{b}}$, Sheng-Jie You ${ }^{\mathrm{c}}$, William E. Price ${ }^{\mathrm{d}}$, and Long D. Nghiem ${ }^{\mathrm{a}}$

${ }^{a}$ Strategic Water Infrastructure Laboratory, School of Civil, Mining and Environmental Engineering, University of Wollongong, Wollongong, NSW 2522, Australia

${ }^{\mathrm{b}}$ Centre for Technology in Water and Wastewater, School of Civil and Environmental Engineering, University of Technology Sydney, Sydney, Broadway, NSW 2007, Australia

${ }^{c}$ Department of Bioenvironmental Engineering and R\&D Centre for Membrane Technology, Chung Yuan Christian University, Chungli 320, Taiwan

${ }^{\mathrm{d}}$ Strategic Water Infrastructure Laboratory, School of Chemistry, University of Wollongong, Wollongong, NSW 2522, Australia

* Corresponding author:

Email: faisal@uow.edu.au, Ph +61 242213054 
Abstract: Alternate cycling of sludge in aerobic, anoxic, and anaerobic regimes is a promising strategy that can reduce the sludge yield of conventional activated sludge (CAS) by up to $50 \%$ with potentially lower capital and operating cost than physical- and/or chemical-based sludge minimisation techniques. The mechanisms responsible for reducing sludge yield include alterations to cellular metabolism and feeding behaviour (metabolic uncoupling, feasting/fasting, and endogenous decay), biological floc destruction, and predation on bacteria by higher organisms. Though discrepancies across various studies are recognizable, it is apparent that sludge retention time, oxygen-reduction potential of the anaerobic tank, temperature, and sludge return ratio and loading mode are relevant to sludge minimisation by sludge cycling approaches. The impact of sludge minimisation on CAS operation (e.g., organics and nutrient removal efficiency and sludge settleability) is highlighted and key areas requiring further research are also identified.

Keywords: Sludge minimisation; oxic-settling-anaerobic; anaerobic side-stream reactor; bacterial predation; endogenous decay; metabolic uncoupling.

\section{Introduction}

Biological treatment is the most widely used approach to managing domestic and industrial wastewaters. It involves the transformation of dissolved and suspended organic matters by a consortium of micro-organisms to gases and settleable biomass or sludge. While biological treatment offers high organic removal efficiency, it also entails significant sludge production, which contains active (live) and inactive (dead) micro-organisms and must be treated prior to disposal to prevent adverse impact on public health and the environment. Sludge treatment in a typical wastewater treatment plants (WWTP) includes thickening, anaerobic or aerobic digestion, and dewatering to decrease sludge volume, odour, pathogenicity, and vector attraction (Tchobanoglus et al., 2003). However, even after treatment, the amount of remaining sludge in dry mass is still significant, thereby representing a major fraction of the total operating cost during wastewater treatment. 
The increase in wastewater treatment coverage in response to sanitary improvement has resulted in consequent increase of sludge production for management and disposal. In 2005, the EU generated 10 million tonnes of dry sludge (Fytili and Zabaniotou, 2008). In 2010, China generated 11.2 million tonnes of dry sludge (Foladori et al., 2010). In Australia, dry sludge production from wastewater treatment increased by about $3 \%$ each year from 0.30 million tonnes in 2010 to 0.33 million tonnes in 2013 (NWC, 2013). Thus, the production of excess sludge from biological treatment is one of the most vexing problems for WWTP operation and necessitates effective management strategies. Further issues arise during the disposal of the treated sludge. In the past, sludge was commonly disposed through landfilling, incineration, and agricultural re-use. Landfilling has become increasingly impractical due to the high cost of land acquisition and tightening of restrictions on landfill operation activities (Wei et al., 2003). Incineration decreases the volume of solids by up to 95\%. However, it requires expensive machinery, consumes non-renewable resources, and has negative public impression (Tchobanoglus et al., 2003). The re-use of sludge as fertilizer or soil conditioner is an appealing option because it adds economic value to waste. However, this practice often requires long distance transport of the treated sludge to the end users. In addition, sludge may contain heavy metals (Tchobanoglus et al., 2003) and trace organic chemicals that are potentially toxic (Clarke and Smith, 2011). Thus, there is a risk of circulation and accumulation of harmful substances in the environment and food products. Therefore, sludge minimisation is generally preferred over sludge treatment as it cascades to a decrease in sludge handling, stabilization, transportation, and disposal expenses.

Considerable research efforts have been devoted to sludge production minimisation during biological wastewater treatment. Sludge minimisation could be achieved via several techniques, namely, control of operating parameters, disintegration of return activated sludge (RAS) by physical, thermal, or advanced oxidation processes (Chu et al., 2009; Foladori et al., 2010; Liu, 2003; Neyens and Baeyens, 2003; Pilli et al., 2011), addition of chemicals that disrupt biomass growth (Liu, 2003), and alternating redox conditions (aerobic, anoxic, and anaerobic sludge cycling regimes) (Foladori et al., 2010). Controlling parameters such as increasing sludge retention time (SRT) and dissolved oxygen (DO) 
concentration, can only yield marginal improvement but may increase plant operation costs (Wei et al., 2003). The disintegration of sludge significantly reduces sludge production, but requires high capital investment and on-going maintenance (Foladori et al., 2010). In addition, the use of chemicals or advanced oxidation processes can introduce potential contaminants to the sludge and effluent streams (Mahmood and Elliott, 2006). Thus, sludge cycling between different redox conditions is arguably the most benign and cost-effective approach to minimise sludge yield. This approach is not new and was first explored by Westgarth et al. (1964), who inserted an anaerobic tank in the return sludge line that resulted in a 50\% decrease in sludge production. Chudoba et al. (1992) made some process modifications to this approach and coined the term "oxic-settling-anaerobic" (OSA). Thus, the generic OSA process can be defined as the recirculation of waste activated sludge (WAS) between (a) an external anoxic or anaerobic and substrate-deficient chamber, and (b) the aerobic and substraterich main bioreactor.

Recent research has demonstrated that OSA could reduce sludge yield by up to 55\% (Chen et al., 2003; Saby et al., 2003). The OSA process is simple and thus it can be readily retrofitted to existing plants as well as implemented in new designs. However, despite its immense potential, the present level of understanding of OSA is still limited. There is a marked contention in the literature on the mechanisms underlying biological sludge reduction (Chen et al., 2003; Chudoba et al., 1992) and influence of key operating parameters including SRT, oxidation reduction potential (ORP), temperature and solid interchange rate and frequency on the performance of OSA and similar approaches.

Excellent reviews on conventional sludge minimisation approaches (Guo et al., 2013; Liu and Tay, 2001; Mahmood and Elliott, 2006; Wei et al., 2003), and specific sludge minimisation techniques, such as thermal treatment (Neyens and Baeyens, 2003), ultrasonication (Pilli et al., 2011), advanced oxidation and chemical addition (Liu, 2003), and ozonation (Chu et al., 2009), are available in the literature. However, none has focused on biological sludge minimisation by OSA and similar sludge cycling schemes. Thus, this paper aims to provide an in-depth discussion on systems that perform aerobic/anaerobic/anoxic cycling by treating RAS in an external oxygen-deficient $\operatorname{tank}(\mathrm{s})$. Differences 
in system configurations and their impact is discussed and related to the degree of sludge minimisation. The discussion focuses on possible mechanisms behind the observed reduction of sludge yield, as well as the pertinent operating parameters that influence sludge minimisation. The impact of the external oxygen-deficient tank on the performance of biological treatment (e.g. chemical oxygen demand (COD) and nutrient removal efficiency) is also systematically assessed. This paper provides a critical analysis of the available literature, identifies gaps in knowledge and highlights areas for future research.

\section{Sludge minimisation: alternating redox conditions vs. other methods}

\subsection{Overview of various sludge minimisation techniques}

During wastewater treatment processes, primary sludge from the primary settling tank easily decomposes in the sludge treatment units. Secondary or waste sludge generated by biological treatment can also be digested but is usually produced in excessive amounts. OSA and other sludge minimisation techniques that are discussed in this review (Table 1) transpire in the wastewater treatment process, i.e. in the main bioreactor or the 'bioreactor-settling tank-RAS' loop. A simple technique to reduce sludge yield is to manipulate key operating parameters (including SRT and DO) during wastewater treatment. Long SRT and high DO concentration decrease biomass growth but require excessive aeration (Wei et al., 2003) (Table 1). Another technique is to disintegrate RAS before it is re-routed back to the main bioreactor. Sludge can be broken up using a number of methods including thermal treatment (heating sludge at 40 to $180^{\circ} \mathrm{C}$ ) (Camacho et al., 2005; Canales et al., 1994; Neyens and Baeyens, 2003), thermochemical treatment (combination of heating and adding acid or base) (Do et al., 2009; Neyens and Baeyens, 2003; Rocher et al., 2001; Uan et al., 2013), ultrasonication (the application of low frequency ultrasonic waves, e.g. $25 \mathrm{kHz}$ or lower) (Vaxelaire et al., 2008; Zhang et al., 2007), ozonation (the application of ozone as oxidizing agent) (Ahn et al., 2002; Kamiya and Hirotsuji, 1998; Yasui et al., 1996), and chlorination (the application of chlorine as oxidizing agent) (Chen et al., 2001b; Saby et al., 2002; Takdastan and Eslami, 2013). The disintegration of sludge by either physical or chemical methods amplifies cell lysis, and the continuous recirculation of lysates results in a net loss of biomass (a process called cryptic growth, 
which is discussed in more detail in Section 4.1). Certain sludge disintegration methods also improve sludge settling and/or dewatering (Table 1), but their common disadvantage is the high capital investment and maintenance cost of additional treatment units. Moreover, advanced oxidation processes such as ozonation or chlorination may result in the production of toxic by-products (Mahmood and Elliott, 2006). Sludge minimisation can also be achieved through the addition of metabolic uncouplers. Energy uncoupling is the detachment of catabolism from anabolism that cuts off energy for cellular propagation (discussed in more detail in Section 4.4). Various halogenated phenols (Low and Chase, 1998; Yang et al., 2003) and 3,3',4',5-tetrachlorosalicylanilide (TCS) (Chen et al., 2002) interfere with metabolic processes and inhibit biomass growth. Nevertheless, the toxicity of phenolic compounds is well known (Clarke and Smith, 2011) and TCS is identified as being bioaccumulative, persistent, and toxic to aquatic organisms (Liu, 2003). Adding these substances to the main biological reactor could compromise the quality of both effluent and waste sludge.

\section{[Table 1]}

\subsection{Sludge minimisation by alternating aerobic/anaerobic/anoxic conditions}

The sludge minimisation techniques described in Section 2.1 have found minimal practical applications due to high capital and operating costs and/or production of undesired by-products. Hence, it is appealing to explore biological sludge minimisation via sludge cycling schemes. The kinetics of biomass growth is described by the following equation:

$$
\frac{1}{Y_{o b s}}=\frac{1}{Y_{\max }}+\frac{S R T \cdot k_{d}}{Y_{\max }}
$$

Equation 1

where $Y_{o b s}$ is the observed sludge yield (i.e. the ratio of biomass formed and substrate consumed), $Y_{\max }$ is the maximum sludge yield, and $K_{d}$ is the decay coefficient (Liu and Tay, 2001). Sludge cycling is a biological technique that utilises the sensitivity of heterotrophic biomass to the availability of oxygen. It has been established that biomass growth slows down as external conditions progress from aerobic to anaerobic state. This could be related to the efficiency of energy generation using different electron acceptors. Microbial propagation is most robust under aerobic conditions because the oxidation of substrate by oxygen gives the maximum amount of free energy. In the absence of oxygen, other compounds such as nitrate, manganese (IV), ferric iron, sulphate, and organic matter can take over as 
electron acceptor, but less energy is generated (Foladori et al., 2010). The typical maximum sludge yield $Y_{\max }$ for aerobic, anoxic, and anaerobic conditions are $0.4,0.3$, and 0.1 (gram of volatile suspended solids (VSS) per gram of COD in the influent, hereafter referred to as VSS/COD), respectively (Foladori et al., 2010; Tchobanoglus et al., 2003).

Conventional activated sludge (CAS) processes that utilise aerobic and anoxic zones have lower sludge production than those that are strictly aerobic. This is evident in intermittently aerated reactors (Foladori et al., 2010) and nitrogen removal systems (Mahmood and Elliott, 2006). Sludge minimisation has been accomplished in CAS by deliberately placing alternating aerobic and anaerobic compartments, as in the case of the "repeated coupling of aerobic and anaerobic CAS" achieving a 64\% less sludge production than a strictly aerobic CAS (Quan et al., 2012). Therefore, it can be surmised that alternating redox conditions are a key component in sludge minimisation.

OSA also depends on alternating redox conditions in the wastewater treatment loop to minimise sludge, except that the biomass inhibiting environment is outside the main bioreactor. The redox conditions in the external tank ranges from anoxic to anaerobic conditions (Chen et al., 2003;

Chudoba et al., 1992; Saby et al., 2003). Aside from being relatively economical, OSA stands out due to its potential to improve the organic and nutrient removal efficiency of CAS and sludge settleability as discussed further in Section 6 (Chudoba et al., 1992; Saby et al., 2003; Ye et al., 2008). Renewed interest in biological sludge minimisation has delivered recently other laboratory- and full-scale sidestream systems whose principal and underlying mechanisms are highly similar to OSA (Section 3).

\section{Sludge cycling between aerobic/anaerobic/anoxic conditions: configurations}

\subsection{CAS-OSA}

The integration of OSA to CAS involves the placement of sludge holding tank in the RAS line (Fig. 1a), which results to the CAS-OSA configuration (An and Chen, 2008; Chen et al., 2003; Chudoba et al., 1992; Saby et al., 2003; Wang et al., 2008; Ye et al., 2008).The holding tank receives all (An and Chen, 2008; Chen et al., 2003; Saby et al., 2003) or most (Chudoba et al., 1992), of the settled sludge, which is depleted in VSS due to prior consumption in the aerobic and settling tanks (Chen et al., 2003). As aeration is not conducted in the holding tank, so the internal conditions range from anoxic 
to anaerobic. In some laboratory-scale implementations, a membrane module is incorporated to the main aerobic tank (Fig 1b), forming a membrane bioreactor (MBR)-OSA, where the membrane retains all settleable solids (An and Chen, 2008; Chen et al., 2003; Saby et al., 2003).

\section{[Figure 1]}

\subsection{SBR with anaerobic SSR}

A configuration (Fig. 1c) that appears frequently in literature is a sequencing batch reactor (SBR) with an anaerobic side-stream reactor (SSR). Chon et al. (2011a; 2011b) and Kim et al. (2012) operated an SBR with four cycles per day with especially-timed FILL, REACT, SETTLE, and DECANT stages. About $10 \%$ of the SBR mixed liquor was allowed to settle, and then transferred to the anaerobic SSR once a day. An equal volume of sludge from the anaerobic SSR was returned to the SBR at the same time. The SBR-anaerobic SSR sludge loop was closed, meaning sludge was only discarded during sampling. Similar to the holding tank of OSA, the anaerobic SSR exposes sludge to oxygen-deficient conditions with limited substrate. However, unlike the OSA process, (i) sludge settling is performed within the SBR instead of in a separate tank, and (ii) settled sludge is loaded to the anaerobic SSR intermittently instead of continuously. Therefore, the SBR-anaerobic SSR requires less space than OSA because aeration and sludge settling occurs in one unit. Moreover, the low loading rate (i.e. 10\% of the total biomass), enables the anaerobic SSR to have long HRT of more than $10 \mathrm{~d}$ (Chon et al., 2011b; Kim et al., 2012).

Interestingly, integration of a modified SBR achieving biological nutrient removal (BNR) with an anaerobic SSR to perform sludge reduction has also been explored (Datta et al., 2009). The modified SBR has additional anaerobic and anoxic states in FILL and REACT stages achieved through nitrogen purging in order to activate denitrification, nitrification, and orthophosphate uptake/release. The authors reported successful nutrient removal and sludge reduction after the attachment of anaerobic SSR. The resulting sludge production due to variations in SBR operation is discussed in more detail in Section 3.5.4. 


\subsection{Cannibal process}

The patented Cannibal ${ }^{\circledR}$ Solids Reduction System by Siemens combines physical and biological methods to reduce sludge production (Johnson, 2008; Sheridan and Curtis, 2004). Its configuration is similar to that of anaerobic SSR, except for the additional physical treatment for return sludge. In fullscale Cannibal processes, about $50 \%$ of the return sludge is routed to a "solids removal module," which contains an intermediate tank, drum screen, and hydrocyclone, that removes grit and other inert solids (Fig. 1d) (Johnson, 2008). The solids collected by the module are compressed and disposed of as often as necessary. After the physical separation of solids, sludge is passed through an anaerobic or anoxic "interchange reactor." In the report of Johnson et al. (2008), the interchange reactor was an SBR (SRT=10 d) that returned sludge to the main bioreactor. The solids removal module could be omitted if the wastewater has very minimal amount of grit and non-biodegradable solids, e.g. dairy wastewater (Sheridan and Curtis, 2004).

Novak et al. (2007) simulated a laboratory-scale Cannibal process without a solids removal step using an SBR as the main reactor. Therefore, their set-up was essentially an SBR-anaerobic SSR (Fig. 1b). Settled sludge $(50 \mathrm{~mL})$ from the SBR, which represented $4 \%$ of the total biomass, was transferred to the anaerobic SSR (HRT=2 d). Due to extensive sludge accumulation in the main reactor, the amount of sludge that was transferred from the SBR to the anaerobic SSR had to be increased to $100 \mathrm{~mL}$. Goel and Noguera (2006) combined a laboratory-scale enhanced biological phosphorous removal (EBPR) SBR with the Cannibal process. Similar to the study by Novak et al. (2007), Goel and Noguera (2006) did not have a solids removal module and their setup can also be described by Fig. 1b. The core of the EBPR process in the SBR was the nitrogen-purged anaerobic FILL stage followed by aerobic REACT (DO concentration $=5 \mathrm{mg} / \mathrm{L}$ ) stage. At the end of each cycle, $10 \%$ of the settled sludge was transferred to the anaerobic SSR. Because sludge was not discarded from the system, the sediment in SBR and the corresponding portion that must be transferred to the anaerobic SSR eventually built up so much that the capacity of the anaerobic SSR had to be increased.

Even though Novak et al. (2007) and Goel and Noguera (2006) aimed to simulate the Cannibal process, their setups did not possess the trademark solids removal module. Moreover, both groups 
employed synthetic wastewater that contained minimal suspended solids. Certain types of real wastewater may possess higher amounts of slowly-biodegradable debris that could contribute to sludge volume. Thus, to date, a thorough analysis of the effect of Cannibal's physical pre-treatment on overall sludge reduction has not been made available in the literature.

\subsection{BIMINEX process}

Coma et al. (2013) attempted simultaneous nutrient removal and sludge reduction by modifying a pilot University of Capetown (UCT) process to include a separate anoxic SSR, forming the patented BIMINEX ${ }^{\mathrm{TM}}$ process (Fig. 1e). The original UCT process employs a succession of anaerobic, anoxic, and aerobic tanks with continuous sludge recycling from anoxic to anaerobic, aerobic to anoxic, and settling to anoxic tanks to enable nutrient removal. In the modified process, the portion of the settled sludge that is customarily returned to the anoxic tank was instead made to pass through the anoxic SSR, and then returned to the anaerobic tank of the main reactor. Maintaining anoxic conditions in the SSR seemed pragmatic because doing so did not interrupt the internal recycle flow that is conducive to nutrient removal. Like the BNR SBR-anaerobic SSR implemented by Datta et al. (2009) (Fig. 1c), the main reactor of BIMINEX ${ }^{\mathrm{TM}}$ was not strictly aerobic. Coma et al. (2013) acknowledged that returning the SSR-treated sludge to the nutrient removal zones possibly influenced sludge reduction, but did not investigate in more detail. BIMINEX ${ }^{\mathrm{TM}}$ is further distinguished from the SBR-anaerobic SSRs because of its continuous loading of settled sludge into the SSR (as opposed to intermittent loading). The implications of loading mode on sludge minimisation by BIMINEX process has not been explained in the literature, however this aspect has been further discussed in Section 3.5.2 in relation to aerobic main bioreactors i.e., CAS in case of CAS-OSA and SBR in case of SBRanaerobic SSR configurations.

\subsection{Performance of various configurations}

\subsubsection{Reduced sludge yield of main reactor due to OSA or SSR}

Adding either an OSA or anaerobic SSR to the main bioreactor (either CAS or SBR) can result in a reduced sludge yield $\left(Y_{o b s}\right) . Y_{o b s}$ of laboratory-scale CAS-OSA (Fig. 1a) ranged from 0.20-0.29 (total suspended solids, TSS/COD) (Chudoba et al., 1992) and 0.53 (mixed liquor suspended solids, 
MLSS/COD) (Wang et al., 2008), which were $40-50 \%$ and $13 \%$, respectively, less than that of a control CAS.(Ye et al., 2008). Chen et al. (2003) and Saby et al. (2003) utilized an MBR-OSA in their investigations to increase the accuracy of sludge yield measurements (Fig. 1b). Their control system was an MBR that regularly discarded excess sludge, and had no settling and holding tanks. Chen et al. (2003) observed that the MBR-OSA system had a sludge production rate of 2.3-3.6 g/d, which was 23-51\% lower than that of the control MBR (2.4 g/d). Saby et al. (2003) reported a $Y_{o b s}$ of $0.18-0.32$ (SS/COD) for an MBR-OSA, which was 20-55\% lower than that of the control MBR (0.40 TSS/COD). Both studies operated the holding tank (OSA) at varying ORP levels $(-250$ to $+100 \mathrm{mV})$ in order to examine the effect of anoxic conditions to sludge yield. Regardless of ORP, the holding tank always decreased sludge production. An and Chen (2008) also operated an MBR-OSA system and noted that the $k_{d}$ of the control MBR $(0.021 / \mathrm{d})$ was significantly lower than those of CAS process, which range from $0.06-0.15 / \mathrm{d}$. However, the $k_{d}$ of the anaerobic holding tank was $0.13 / \mathrm{d}$, which was much higher than typical anaerobic coefficients of $0.02-0.04 / \mathrm{d}$. These findings suggested that sludge minimisation in MBR-OSA occurred largely in the holding tank.

Various degrees of sludge minimisations by SBR-anaerobic SSR systems (Fig. 1c) have been reported. For instance, Chon et al. (2011a; 2011b) reported a $Y_{\text {obs }}$ of 0.11-0.17 VSS/COD. In a study attempting to simulate a Cannibal process, Novak et al. (2007) attained a similar $Y_{\text {obs }}(0.11 \mathrm{VSS} / \mathrm{COD})$ as that of Chon et al. (2011a; 2011b). The sludge yield of these systems was generally lower than a standalone SBR with no sludge wastage.

The sludge yield of a pilot UCT system decreases by the integration of an anoxic SSR, as demonstrated by BIMINEX® (Fig. 1d) (Coma et al., 2013). Reducing the excess sludge of a BNRtype process is challenging due to the mechanism of phosphorous removal, which relies on polyphosphate accumulating organisms (PAO) to release and uptake orthophosphate under anaerobic and aerobic conditions, respectively. To successfully eliminate phosphorous from the system, adequate amounts of orthophosphate-rich sludge must be regularly discarded (Tchobanoglus et al., 2003). This contradicts the principle of excess sludge reduction. Nonetheless, Coma et al. (2013) demonstrated 
that completely treating the return sludge in the anoxic SSR decreased the sludge yield of a full-scale UCT from 0.51 to $0.33 \mathrm{VSS} / \mathrm{COD}$, i.e. by $18.3 \%$.

\subsubsection{Effect of loading mode}

It is interesting to compare the performance of OSA and anaerobic SSR in reference to the sludge loading mode to the anoxic or anaerobic external tank. Table 2 lists the $Y_{o b s}$ for OSA and SSR in different studies. A direct comparison of $Y_{o b s}$ could not be performed because the studies quantified biomass as either TSS or VSS. If it were assumed that VSS/TSS ratio is $0.70-0.85$, which is the normal range for activated sludge processes (Sperling, 2007), it could be inferred that anaerobic SSR have lower sludge production than OSA. This could be a consequence of sludge loading mode (continuous versus intermittent). Novak et al. (2011) found that feeding the anaerobic SSR with 10\% of settled sludge from SBR in 5 min (fast feed) resulted to lower $Y_{o b s}$ than feeding it with the same amount of sludge for $4 \mathrm{~h}$ (slow feed). They hypothesized that fast feeding caused higher microbial activity and sludge reduction within the anaerobic zone than the slow feeding. It is possible that anaerobic SSR, which essentially has a fast feeding mode, also have higher microbial activity. However, the impact of other factors compared in Table 2 cannot be completely discounted. For one, it is apparent that SBR-anaerobic SSR systems are usually operated at higher SRT than CAS- and MBR-OSA systems, and it is well-known that SRT is inversely proportional to heterotrophic sludge yield (the effect of SRT on OSA is discussed in more detail in Section 5.1). Hence, a study that systematically compares the two types of sludge loading mode is necessary to confirm their effect on sludge minimisation.

\section{[Table 2]}

\subsubsection{Effect of sludge recirculation}

In general, biomass decreases under starvation conditions within OSA or SSR. However, evidence suggests that reduction will only be maximized when sludge is returned to the aerobic main reactor, where further decay occurs (Chon et al., 2011a; Chon et al., 2011b; Kim et al., 2012). Hence, the recirculation of sludge between the main bioreactor and external anoxic or anaerobic tank is an important feature of OSA and anaerobic SSR systems that propels sludge minimisation. Sludge 
recirculation leads to several sludge reduction mechanisms including cryptic growth, extracellular polymeric substances (EPS) destruction, and feasting/fasting, which are discussed in greater detail in Section 4.

Strong evidence regarding the impact of sludge recirculation emerges when the performance of OSA and anaerobic SSR systems are compared with anaerobic digesters. These are commonly employed in WWTPs to promote the growth of acid- and methane-forming bacteria that transform solids into low molecular weight compounds and gases. The SRT of digesters, which could range from 10-90 d, are maintained through regular sludge wastage (Tchobanoglus et al., 2003). Chon et al. (2011a; 2011b) and Kim et al. (2012) showed that the sludge production of SBR with aerobic and anaerobic SSR was less than those of SBRs with single pass anaerobic and aerobic digesters. The anaerobic SSR was fed with sludge that was concentrated from $10 \%$ of the mixed liquor (MLSS $=2000-2500 \mathrm{mg} / \mathrm{L}$ ) once per day and recirculated back to the SBR. The SRT of the digesters were maintained at $10 \mathrm{~d}$ through regular sludge wastage. The $Y_{\text {obs }}$ of the SBR-anaerobic SSR (0.16 VSS/COD) was lower than that of the anaerobic digester (0.11-0.17 VSS/COD) by $49-54 \%$, and that of the aerobic digester $(0.27-0.33$ VSS/COD) by $36-40 \%$. Novak et al. (2007) found that the $Y_{\text {obs }}$ of SBR-anaerobic SSR (0.11-0.15 $\mathrm{VSS} / \mathrm{COD}$ ) was $46-61 \%$ less than that of an SBR with a single pass aerobic digester (0.28 VSS/COD) from which sludge was wasted. It is notable that the $Y_{o b s}$ of the aerobic digester in the study of Novak et al. (2007) was similar to those of other studies with comparable configurations (Chon et al., 2011a; Chon et al., 2011b; Kim et al., 2012).

Interestingly, the $Y_{\text {obs }}$ of an anaerobic SSR was only marginally lower than an aerobic SSR (0.16 VSS/COD), i.e. by about 2.5\% (Chon et al., 2011b; Kim et al., 2012). The authors stressed that the SBR-anaerobic SSR had the least sludge yield among five systems including SBR-aerobic SSR, SBRanaerobic digester, SBR-aerobic digester, and SBR without sludge wastage. However, they did not expound on the slight difference in the performance due to anaerobic and aerobic SSRs. This is an interesting finding because it deviates from the widely-accepted belief that oxygen deprivation is a pre-requisite to sludge reduction. 


\subsubsection{Effect of the type of the main reactor}

Ideally, the OSA/anaerobic SSR could be appended to any type of wastewater treatment bioreactors. Most laboratory-scale studies employed an aerobic tank as the main bioreactor, and derived sludge reduction mechanisms from this specific configuration. There is not much information on the effect of OSA/anaerobic SSR to more complex main bioreactors such as those that have integrated anaerobic, anoxic, and aerobic compartments for nutrient removal. Goel and Noguera (2006) compared (i) a control EBPR SBR (SRT=10 d), and (ii) an EBPR SBR-anaerobic SSR with no sludge wastage (Fig. 1c). The $Y_{\text {obs }}$ of reactor with anaerobic SSR was $0.16 \mathrm{TSS} / \mathrm{COD}$, which was $16 \%$ higher than that of the control (0.19 TSS/COD). Here, sludge reduction brought about by the anaerobic SSR to the EBPR process was relatively small.

To explore the feasibility of simultaneous nutrient removal and sludge reduction, Datta et al. (2009) compared two systems: (i) a BNR SBR-anaerobic SSR (Fig. 1c), and (ii) a BNR SBR with anaerobic digester from which sludge was discarded. The overall sludge yield, i.e the combination of the yield of the SBR, yield of anaerobic SSR or digester, and biomass loss due to sampling and effluent, was calculated. The yield of the system with SSR was $0.17 \mathrm{TSS} / \mathrm{COD}$, which was $63 \%$ lower than the system with digester ( $0.43 \mathrm{TSS} / \mathrm{COD})$. The exposure of sludge to various conditions in the main reactor might trigger sludge reduction mechanisms that are different from those that occur at strictly aerobic reaction. Datta et al. (2009) pointed out that greater sludge reduction occurred when the SBR was operated at anaerobic-aerobic-anoxic-aerobic mode than anaerobic-aerobic-anoxic mode. The authors suggested that the state of the sludge that enters the anaerobic SSR was relevant to the sludge reduction process as per the mechanism proposed by Novak et al. (2007). According to Novak et al. (2007), the movement of recycled biomass from aerobic to anaerobic conditions is key to the release of Fe and solubilisation of organic matter. Therefore, transferring aerated biomass to the anaerobic SSR caused additional sludge destruction than transferring anoxic biomass. However, no further data was provided to support this theory.

The studies of Goel and Noguera (2006) and Datta et al. (2009) demonstrate that BNRs could also achieve sludge reduction through anaerobic SSRs. BNRs as the main reactors might experience 
growth trends that are distinct from the aerobic bioreactors when coupled to anaerobic SSRs. The effect of having an aerated tank prior to the SSR on Fe release and organic matter solubilisation has already been raised but not investigated in detail (Datta et al., 2009). It is possible that anaerobic and anoxic environments impact cellular metabolism and bacterial ecology. However, the relation of these phenomena with sludge reduction in OSA or SSR systems has not been investigated to date.

At this point, it is interesting to compare the sludge yield of aerobic and BNR bioreactors after the addition of anaerobic SSR (Table 3). The $Y_{\text {obs }}$ values could not be compared outright because of the variance in the unit of biomass in different studies. Because VSS is always less than TSS, the data in Table 3 suggests that, as the main reactor, BNRs have less sludge yield than aerobic bioreactors. This role of the main bioreactor in OSA and anaerobic SSR sludge reduction systems is a viable avenue of study, especially since higher performance might be achieved by bioreactors with further internal cycling.

\section{[Table 3]}

\section{Possible mechanisms minimising sludge production}

Fig. 2 illustrates the cycle of biomass growth in CAS fed with wastewater, which contains soluble biodegradable and non-biodegradable compounds. Biomass consumes the biodegradable portion to generate energy for cell maintenance and growth. A small amount of non-biodegradable substance from wastewater and cell lysis accumulates in the mixed liquor. The growth cycle culminates with cell death, and starts anew using fresh substrate and the biodegradable portion of lysates. OSA minimises sludge by slowing down cell growth, but the means by which this occurs is unclear. It is suggested that OSA unhinges the link between bacterial catabolic and anabolic pathways (Ahn et al., 2002; Chudoba et al., 1992). There is also evidence that transformations in the ecology of activated sludge, such as domination of slow growing bacteria or proliferation or bacteriovores underlie the loss of biomass (Chudoba et al., 1992; Ye et al., 2008). Sludge reduction mechanisms that have been reported in the literature, namely, enhanced endogenous decay, destruction of EPS, biomass feasting/fasting, energy uncoupling/spilling, selection of slow-growing bacteria, and predation on bacteria by higher organisms, occurs at various points in the biomass growth cycle. It is difficult to 
isolate a single cause because of the circumstances unique to OSA, i.e. (i) sludge cycling that intermixes aerobic and anaerobic sludge, (ii) deprivation of substrate in the aerobic zone, and in some cases (iii) extended SRT, all of which could trigger a variety of cellular and ecological responses. Hence, sludge minimisation can be attributed to more than one mechanism (Wang et al., 2008). It is also possible that these mechanisms are overlapping. For instance, it is proposed that the destruction of extracellular polymeric substances (EPS) under anaerobic conditions eventually lead to sludge reduction (Park et al., 2006). The remnants of EPS could also serve as substrate in the aerobic reactor, which further minimises sludge yield (Wei et al., 2003). In this scenario, both EPS destruction and aerobic endogenous decay contribute to sludge reduction.

\section{[Figure 2]}

\subsection{Enhanced endogenous decay}

Evidence from the literature suggests that OSA is conducive to endogenous decay, which refers to the overall loss in biomass weight and activity in the absence/shortage of substrate (Hao et al., 2010; Liu and Tay, 2001; Wei et al., 2003). Endogenous decay increases the concentration of organic matter and nutrients in the supernatant (Equation 2).

$$
\mathrm{C}_{5} \mathrm{H}_{7} \mathrm{NO}_{2}+5 \mathrm{O}_{2} \rightarrow 5 \mathrm{CO}_{2}+2 \mathrm{H}_{2} \mathrm{O}+\mathrm{NH}_{3}+\text { organic matter }+ \text { energy } \quad \text { Equation } 2
$$

During OSA, a portion of WAS is subjected to extended substrate-limitation. This induces biomass decay and limits cell production in favour of expending energy exclusively on motility, materials transport, and other basic activities necessary to maintain homeostasis (Hao et al., 2010). This process, which is called maintenance metabolism (Fig. 2), decreases sludge yield (Liu and Tay, 2001; Wei et al., 2003). The same process occurs in systems that have high SRT and low F/M ratio such as MBRs (under long SRT operation conditions) and digesters, wherein low sludge reduction is also observed (Wei et al., 2003). Chen et al. (2003) suggested that biomass decay in the OSA tank is the most prevalent sludge reduction mechanism in MBR-OSA on the basis that overall sludge yield $Y_{S}$ of the system deteriorated even though the sludge decay coefficent $K_{d}$ of the MBR stayed the same. Chen et al. (2003) also attribute the decrease in sludge yield to the decrease in the sludge decay 
coefficient $K_{a}$ of OSA tank. Nonetheless, it can be argued that OSA only retains a relatively small portion of biomass temporarily (i.e. biomass is eventually returned to the aeration tank), yet achieves lower sludge yields than single pass digesters (Kim et al., 2012). Sludge cycling is clearly a major aspect of sludge reduction in OSA.OSA is not completely devoid of any substrate. This is because cell lysis releases biodegradable low molecular weight compounds that could be utilized by certain bacteria for propagation - a process called cryptic growth (Quan et al., 2012; Wei et al., 2003). Nonetheless, a fraction of the organic load is lost when they are converted to respiration products (e.g. $\mathrm{H}_{2} \mathrm{O}, \mathrm{CO}_{2}, \mathrm{~N}_{2}$, etc.). Hence, there is a net loss of endogenous substrate when the cycle of cell lysiscryptic growth is repeated. This may also cause an incremental decrease in biomass in OSA (Wei et al., 2003).

\subsection{Destruction of EPS}

Microbial populations in activated sludge are sustained in complex aggregates or flocs consisting of bacteria, organic matter, and inorganic compounds. Key to the formation of these flocs are EPS, which are proteins, polysaccharides, lipids, DNA, and other organic macromolecules from bacteria, that serve as the matrix necessary for intercellular adhesion, communication, and propagation. They also provide protection from bactericides and physical stresses (Liu and Fang, 2003). Some studies suggest that sludge reduction in sludge cycling schemes is rooted on the anaerobically-driven degradation of EPS into smaller forms, which are degraded with ease when sludge is recycled back to the aerobic reactor (Chon et al., 2011b; Novak et al., 2007). Novak et al. (2003) confirmed that EPS are released from floc under anaerobic conditions, and the proteins and polysaccharides that accumulate in the supernatant originate from EPS. The mechanism of EPS degradation is unclear, but the findings of Ayol et al. (2008) showed that addition of $\alpha$-amylase and $\beta$-glucanase improved the hydrolysis of EPS, which led to floc destruction (Ayol et al., 2008; Novak et al., 2003).

There is a strong correlation between Fe concentration and VSS reduction in the anaerobic phase (Park et al., 2006). This is explained by the association of EPS with certain cations in the floc. Cations function as a "bridge" that connects negatively-charged EPS and cells, and has been found to positively affect flocculation (Liu and Fang, 2003). It was found that mostly Fe-bound proteins are 
released during anaerobic digestion, whereas mostly $\mathrm{Ca}^{2+}$ and $\mathrm{Mg}^{2+}$-bound polysaccharides are released during aerobic digestion (Supplementary Data Fig. S1) (Novak et al., 2003; Park et al., 2006). Similar trends have been observed in the Cannibal process (Novak et al., 2007). The mechanism was affirmed by the high oxygen uptake rate of the post-Cannibal supernatant, which implies excellent biodegradability. Chon et al. (2011a) also explained sludge reduction in an SBRanaerobic SSR through EPS degradation. Based on the employed extraction techniques, the most relevant EPS were narrowed down as Al- or Fe-bound. Thus far, literature has demonstrated that the cation content of sludge might be a good indicator of biodegradability of EPS at certain phases (Park et al., 2006). Further investigations about the preferential release of cation-bound EPS must be undertaken to fully understand the steps involved in the process and, if possible, to engineer controlled flocs disintegration.

Chen et al (2003) studied the impact of the soluble portion of EPS, which is also referred to as soluble microbial products (SMP), on sludge reduction of MBR-OSA. They compared sludge from OSA that was washed (negligible soluble COD) and not washed (soluble COD $=70 \mathrm{mg} / \mathrm{L}$ ) with water, and found that both samples had similar sludge yields (MLSS/COD). With this finding, they concluded that SMP had no effect on biomass growth. However, it can be argued that the integrity of the floc structure was maintained despite washing and thus, the effect of EPS was not determined.(Wang et al., 2008)

\subsection{Energy uncoupling}

Synthesizing new molecules and cells (anabolism) requires free energy, which is made available by oxidizing organic substrate (catabolism). In aerobic regimes, these two interconnected processes are driven by the phosphorylation/de-phosphorylation of adenosine triphosphate (ATP), which stores large amounts of energy in its covalent bonds (Fig. 3a). The "un-coupling" of catabolism and anabolism occurs when the energy produced by catabolism is not sufficient or directed away from anabolism. This can be achieved by addition of chemical uncouplers (e.g. protonophores and heavy metals) (Liu, 2003), excessive substrate loading (Liu, 1996), and temperature shocks (Foladori et al., 2010), among others. OSA also causes energy uncoupling by alternating bacterial growth conditions. 
In the anaerobic zone, bacteria are driven towards maintenance metabolism and ATP production is low due to absence of substrate and efficient electron acceptors (e.g. oxygen). Sludge reduction occurs when biomass is returned to the aerobic tank, during which bacteria preferentially replenish energy stores instead of synthesizing new cells. This was confirmed by Chudoba et al. (1992) via demonstrating that ATP concentration significantly decreased after passing through the anaerobic zone. Other non-OSA systems involving phase cycling (e.g. baffled reactor with three alternating anaerobic cycles and sludge treatment with alternating anoxic and aerobic cycles) have also cited energy uncoupling as means for apparent sludge reduction (Quan et al., 2012; Troiani et al., 2011). Quan et al. (2012) operated a sludge-reducing baffled reactor with eight alternating aerobic and anaerobic tanks, and demonstrated that the ATP concentration at the subsequent aerobic tank is less than that of the previous one, indicating the depletion of stored energy in the biomass. (Chen et al., 2003)

\section{[Figure 3]}

\subsection{Feasting/fasting}

It is possible that OSA reduces sludge via alternating "fasting" and "feasting" conditions (Chen et al., 2001a) (Fig. 3b). Activated sludge undergoes a state of fasting in the OSA tank, wherein cells use stored energy for maintenance metabolism. When starved sludge is returned to the aerobic main reactor, cells begin feasting on available substrate to replenish energy stores (Chen et al., 2001a; Chen and Liu, 1999). According to Chen et al. (2001a), this leads to energy uncoupling and ultimately, sludge minimisation. They tested this theory by inducing 2 -h fasting on sludge samples from aerobic batch and continuous flow reactors. Fasting conditions was accomplished by (i) withholding substrate and (ii) adjusting sludge ORP in the range of $-100 \mathrm{mV}$ to $100 \mathrm{mV}$ by means of nitrogen gas purging and addition of titanium (III) citrate buffer. The carbohydrate content of starved sludge decreased by about $20 \%$, but the ATP content was unchanged. Then, the starved sludge samples were returned to the aerobic state by increasing DO concentration to more than $5 \mathrm{mg} / \mathrm{L}$. At this point, they were also overloaded with substrate (4.5-5.6 $\mathrm{mg}$ COD/mg MLSS). The phenomenon of sludge feasting was evidenced by a sharp increase in specific oxygen uptake rate (SOUR), which indicated high levels of substrate oxidation. Glucose did not accumulate and ATP decreased by $52-62 \%$, which signifies that 
internal energy levels were not restored. In that study, fasting/feasting was not accompanied by a decrease in sludge yield, thereby somewhat discrediting this theory. Nonetheless, it is still arguable that variance in microbial activity in fasting and feasting conditions might contribute to sludge reduction. For instance, Hao et al. (2010) showed that during starvation conditions bacterial communities will produce lytic enzymes that degrade cell walls as a survival response. Bacteria could self-oxidise to generate energy for cell maintenance, leading to programmed cell death and biomass weight.

\subsection{Selective enrichment of bacterial populations}

The variations in reactor configurations and operating conditions between the main reactor (either CAS or SBR) and the OSA component have a profound effect on bacterial diversity, which plays a role in biomass growth. Using polymerase chain reaction-denaturing gel gradient electrophoresis (PCR-DGGE) analysis of the 16S ribosomal DNA (rDNA), Wang et al. (2008) demonstrated that CAS-OSA possessed a wider range of bacterial species than CAS. Also using PCR-DGGE, Kim et al. (2012) showed that the SBR (of an SBR-anaerobic SSR) had a "normal" aerobic bacterial profile, whereas the anaerobic SSR possessed a profile similar to a conventional anaerobic digester. For instance, the anaerobic SSR contained Spirochaetes, a gram-negative phylum that grows exclusively in anaerobic digesters. Due to sludge interchange, bacteria that are not commonly selected in aerobic conditions have opportunity to thrive in OSA. This includes organisms that have low growth rates. (Chen et al., 2003)Goel and Noguera (2006) noted an enrichment of slow-growing bacteria such as PAO and fermenters in the EBPR SBR due to sludge interchange with anaerobic SSR. Aside from having long incubation, fermenters can accelerate decay by its ability to decompose flocs. Quan et al. (2012) also found hydrolytic-fermentative bacteria and acetogenic bacteria in the anaerobic compartments of a baffled reactor with repeated sequences of aerobic and anaerobic conditions. Meanwhile, Chudoba et al. (Chudoba et al., 1992) also noted that CAS-OSA was dominated by PAO (50-60\% of the total bacterial population). However, Chen et al. (2003) rejected the relevance of slow growing bacteria on sludge reduction on the basis that MBR and MBR-CAS had similar growth rates. Nonetheless, they noted that bacterial populations of the two systems may differ due to variation in 
ORP. Moreover, the MBR-OSA demonstrated a sharp change in sulphate concentration at ORP of less than $-250 \mathrm{mV}$, which indicates the activity of slow growing sulphate reducing bacteria. At the moment, the influence of slow-growing bacteria on sludge reduction in OSA is still unclear. Further investigations on the evolution of microbial population upon integration of OSA and anaerobic SSR will provide greater insight on their role.

\subsection{Predation of bacteria by higher organisms}

Aside from bacteria, activated sludge contains predatory eukaryotes such as protozoa and small metazoa. The primary predators are ciliates, which employ ciliary currents to feed on bacteria that are either free-floating or loosely-bound on the flocs surface (Madoni, 1994). Some researchers have successfully employed these organisms to reduce sludge yield through biomass consumption. A commonly reported system is a two-stage process involving a bacteria-rich suspended reactor followed by a predator-rich suspended or biofilm reactor (Ghyoot and Verstraete, 2000; Lee and Welander, 1996). In this setup, the extent of sludge reduction has a direct relationship with (i) the number of protozoa, and (ii) the proliferation of free-floating bacteria that the protozoa are capable of capturing (Ghyoot and Verstraete, 2000; Lee and Welander, 1996). Other organisms that have been distinguished as relevant biomass feeders are metazoan rotifers, oligocheate worms, and annelids (Ratsak and Verkuijlen, 2006).

There is a possibility that significant predation on bacteria occurs in OSA. Conditions unique to OSA have potential to promote protozoan growth and activity. First, aerobic to anoxic cycling enhances protozoan diversity. Dubber and Gray (2011) observed that short exposure (6 h) to anoxic conditions results to additional niche for protozoa, and increases the number of surviving species. Extended exposure to anaerobic conditions decreases diversity, but allows Vorticella, a species that is wellknown to tolerate low dissolved oxygen (Madoni, 2003), to thrive. The impact of such variations on sludge yield is thus far unknown. Second, the high SRT that is employed in some OSA (e.g. 19.5-30 d (Saby et al., 2003)) and SBR-anaerobic SSR (e.g. 70-100 d (Chon et al., 2011b; Novak et al., 2007)), might be conducive to predator growth. Lee and Welander (1996) stressed on the importance of keeping the SRT of the predator-rich reactor eight times longer (SRT=6-24 h) than the bacteria-rich 
reactor (1-3 h). Microbial analysis revealed that both main reactor and OSA (SRT=5.5-11.5 h)

contained protozoa, such as Paramecium candatum and Vorticella, and metazoa, such as Rotifera and Nematoda (Ye et al., 2008). However, the contribution of predators on sludge reduction in OSA has not been assessed. Chen et al. (2003) rejected predation as a relevant sludge reduction mechanism in OSA on the basis that worms were not found in any of the reactors. However, the role of protozoa was not accounted for, and warrants further investigation.

\section{Operating parameters affecting sludge reduction}

Improvements in sludge reduction associated with CAS-OSA range from 18.87-28.30\% (Wang et al., 2008 ) and 40-50\% (Chudoba et al., 1992) in terms of sludge production (suspended solids per COD removed), or $83 \%$ (An and Chen, 2008) and $14-33 \%$ (Ye et al., 2008) reduction in terms of sludge production rate (suspended solids per unit of time). The wide variation in performance could be attributed to variations in feed, and oxygen concentration and SRT in OSA.

\subsection{SRT}

In general, sludge yield is inversely proportional to SRT as depicted in Equation 1 (Liu and Tay, 2001; Wei et al., 2003). At longer SRT, endogenous decay dominates. Cryptic growth is possible from the biodegradable fraction of lysates that have been released into the supernatant. However, lysates also have slowly- or non-biodegradable fractions, e.g. peptidogylcans from cell walls, which accumulate in the reactor over time. This also impacts the degree of biomass starvation and production (Liu and Tay, 2001). Operation at SRT of infinity (no sludge wastage), which is easily achievable in MBRs, can significantly reduce sludge yield (Rosenberger et al., 2000). Nonetheless, it

is not always practical to maintain a very long SRT due to its negative effect on sludge characteristics and aeration costs (Wei et al., 2003).

Long SRT has also been linked to predation on bacteria by protozoa, metazoa, and other higher organisms (Lee and Welander, 1996). However, the route from predation to sludge reduction is not mapped clearly, and the proliferation of predators is difficult to predict and monitor. For instance, Rosenberger et al. (2000) operated an MBR with no sludge wastage and achieved zero sludge yield but only detected low concentrations of protozoa in the reactor. 
Fig. 4 shows the sludge yield (in terms of TSS or VSS/COD) of various studies as a function of SRT. The incorporation of an external tank in the return sludge line prolongs the total time spent by sludge within the treatment loop. Subscribing to the principle of endogenous decay, Saby et al. (2003) observed an incremental decrease in $Y_{o b s}(0.40,0.32,0.22 \mathrm{TSS} / \mathrm{COD})$ in response to increasing the SRT of an MBR-OSA system (19.5, 25.9 and 30.4 d). Coma et al. (2013) also found that the $Y_{o b s}$ of BIMINEX decreased from 0.513 to $0.434 \mathrm{VSS} / \mathrm{COD}$ when total SRT was increased from 16.5 to 23.3 d. SBR-anaerobic SSR systems were able to operate at extremely high SRT (70-100 d) by avoiding sludge wastage, and attained low $Y_{\text {obs }}(0.15$ to $0.16 \mathrm{VSS} / \mathrm{COD})$.

There are also findings that contradict typical SRT trends. Chudoba et al. (1992) increased the SRT of a CAS-OSA from 5 to $12 \mathrm{~d}$ with organic loading of 2 and $1 \mathrm{~kg} \mathrm{COD} / \mathrm{kg}$ TSS/d, respectively, and observed a decrease in sludge yield. They explained that higher organic loading enhanced metabolic uncoupling. A direct comparison could not be made because two parameters (organic loading and SRT) were changed at the same time. Ye et al. (2008) operated an OSA coupled with a CAS at 5.5, 7.6, and $11.5 \mathrm{~h}$, which caused the main tank to have sludge production rates of $1.84,1.6$, and 2.06 SS/d, respectively. The authors identified an SRT of $7.6 \mathrm{~h}$ as the optimal condition for sludge minimisation. However, it was unclear why sludge production had a non-linear relationship with SRT, deviating from classical biomass growth kinetics. Furthermore, Chen et al. (2003) operated an MBROSA with a total SRT of $17 \mathrm{~d}$ but varying ORP levels, and found that sludge yield decreased with decreasing ORP. These findings suggest that factors other than SRT may have greater impact on sludge minimisation.

As previously pointed out in Section 3.5.2, SBR-anaerobic SSR systems tend to have higher SRT than the OSA systems. However, the superior performance of SBR-anaerobic SSR cannot be solely attributed to high SRT alone. This is because the sludge yield of SBR-anaerobic SSR is still lower than SBR with no sludge wastage, i.e. near-infinite SRT. Chon et al. (2011a; 2011b) showed that the $Y_{o b s}$ of an SBR-anaerobic SSR with a total SRT of $74 \mathrm{~d}$ (0.11-0.17 VSS/COD) was 4-27\% lower than that of a control SBR with an SRT of $81 \mathrm{~d}(0.14-0.186$ VSS/COD). Similarly, Novak et al. (2007) demonstrated that the $Y_{\text {obs }}(0.11 \mathrm{VSS} / \mathrm{COD})$ of their Cannibal SBR-anaerobic SSR was $20-45 \%$ lower 
than that of an SBR with infinite SRT (0.2 VSS/COD). This means that while high SRT benefits endogenous decay, it is not sufficient to explain sludge minimisation in an integrated SBR-anaerobic SSR. Saby et al. (2003) pointed out that under the same anoxic environment, their holding tank's SRT (10.4 h) was much longer than that of Chudoba et al. (1992) (3h), and thus had lower sludge production rate. They indicated that in addition to ORP, the time spent by sludge in either aerobic or anoxic conditions govern sludge yield.

\section{[Figure 4]}

\subsection{ORP}

ORP reflects the net charge of all ions in a solution, and measures the solution's propensity to gain or lose electrons relative to another solution or substance. The presence of oxidizing agents such as oxygen increases or makes the ORP value more positive. On the other hand, reducing agents such as organic matter decrease or make ORP more negative. By this virtue, ORP is commonly utilized to obtain a qualitative assessment of the oxygen concentration in a reactor. There are no standard or literature ORP values for anoxic or anaerobic conditions. An aerated reactor has an ORP value of greater than $+50 \mathrm{mV}$. An anoxic reactor, wherein nitrate or nitrate replaces oxygen as an electron donor, has an ORP value of between +50 and $-150 \mathrm{mV}$ (Saby et al., 2003). An anaerobic reactor is realized when dissolved oxygen and inorganic nitrogen are unavailable, and it has an ORP level of less than $-150 \mathrm{mV}$ (Khanal and Huang, 2003).

Exposing sludge to anoxic or anaerobic conditions, i.e. successively lower ORP, decreases sludge yield (Table 4). In an MBR-OSA system, Saby et al. (2003) observed that ORP values of $+100,-100$, and $-250 \mathrm{mV}$ in the holding tank corresponded to $Y_{\text {obs }}$ of $0.32,0.22,0.18 \mathrm{MLSS} / \mathrm{COD}$. However, variations in ORP were accompanied by variations in SRT, which may also influence sludge yield. Chen et al. (2003) observed $Y_{\text {obs }}$ of 0.3, 0.22, and 0.19 MLSS/COD when the SRT of an MBR-OSA was maintained at $17 \mathrm{~d}$ while the ORP levels were kept at $+100,-100$, and $-250 \mathrm{mV}$, respectively. Both cases suggest that lower ORP is more conducive to sludge reduction.

Reported ORP values of the anoxic SSR of BIMINEX and selected CAS-OSA and MBR-OSA holding tanks are shown in Table 4. It is difficult to compare $Y_{\text {obs }}$ across different studies because SRT 
also varied. Nonetheless, it can be inferred from the data of Chudoba et al. (1992), Saby et al. (2003), and Chen et al. (2003) that regardless of low or high SRT, the anaerobic ORP level of $-250 \mathrm{mV}$ resulted to the lowest $Y_{\text {obs }}$ values (0.2-0.29 TSS/COD). Furthermore, similar sludge yield (0.32 and 0.33 TSS/COD) was obtained from OSA and BIMINEX with anoxic ORP level of -100 to $-150 \mathrm{mV}$. Troiani (2011) pointed out that it is difficult to maintain the ORP at a certain value. They operated a full-scale bioreactor maintaining alternate redox conditions in the sludge line: two ranges of ORP e.g., -400 to $-200 \mathrm{mV}$ (to favour facultative anaerobic biomass) and -200 to $+50 \mathrm{mV}$ (to favour facultative aerobic biomass) were applied. Interestingly, they found that maintaining these ORP ranges for equal duration resulted to the least growth yield of 0.09 (total volatile solids, TVS/COD). This could have two important implications for the operation of OSA or similar configurations: first, an ORP range sufficiently activates sludge reduction activities (as opposed to a strict ORP level), and second, alternating anoxic and anaerobic stages in OSA or SSR could be more beneficial than maintaining either stage alone.

\section{[Table 4]}

\subsection{Temperature}

Alternating redox conditions have been mostly operated at controlled temperatures $\left(20\right.$ to $\left.25^{\circ} \mathrm{C}\right)$ (Chen et al., 2003; Chon et al., 2011b; Chudoba et al., 1992; Goel and Noguera, 2006; Novak et al., 2007; Wang et al., 2008; Ye et al., 2008) or ambient temperatures (Coma et al., 2013; Troiani et al., 2011). Yet, it is well-known that significant sludge reduction could occur at higher temperatures. For instance, floc destruction in thermophilic aerobic and anaerobic digesters is attributed to kinetic acceleration of biochemical reactions and selection of thermophilic bacteria that could induce enzymatic hydrolysis of cell walls (Foladori et al., 2010). Interestingly, Yang et al. (2011) used surface response methodology to model sludge reduction in alternating aerobic/oxygen-limited environment over the range of $20-30{ }^{\circ} \mathrm{C}$, and found that the ideal temperature is $29^{\circ} \mathrm{C}$. While high temperature supports uncoupled metabolism (Foladori et al., 2010), extreme heat could impact biological activity and sludge properties. It should be noted that $29{ }^{\circ} \mathrm{C}$ is slightly higher than what is 
usually adopted in OSA as described in the literature. It may be worthwhile to explore the effect of a range of temperatures on energetic uncoupling in OSA.

\subsection{Sludge return ratio}

In most laboratory-scale studies, the amount of settled sludge is either completely (in conventional OSA) (Chen et al., 2003; Chudoba et al., 1992) or partially (less than 10\% by volume, in anaerobic SSR) returned to the main wastewater treatment tank. Coma et al. (2013) explored the effect of varying the percentage $(0,10,50$, and $100 \%$ by volume) of sludge returned from an anoxic SSR to the anaerobic tank of a UCT (BIMINEX ${ }^{\circledR}$ ), and achieved the maximum sludge reduction of $18.3 \%$ by $100 \%$ return. Hence, it is worthwhile to explore the effect of increasing the sludge loading rate to the anaerobic SSR, which usually accepts less than 10\% of settled sludge (Chon et al., 2011a; Chon et al., 2011b). Sun et al. (2010) returned 10\% of sludge per day from anaerobic SSR to SBR (main tank), but varied the return frequency from once per day to four times per day. Increasing the frequency of sludge return (at the cost of decreasing the amount at each return) decreased MLSS of the SBR by $30 \%$. It was also observed that the total COD (TCOD) in the SSR decreased by $67 \%$, indicating that the degradation of organic matter was intensified. This is opposite to what was previously found in a similar configuration (Novak et al., 2007), but the authors did not speculate on the underlying cause and implications for sludge reduction. Nonetheless, it can be inferred that incremental return of sludge could alter decay processes.

\section{Impact of sludge reduction on wastewater treatment efficiency}

\subsection{Effect on COD removal}

Efficient sludge minimization must be accomplished without compromising effluent quality. An issue that may arise in the process of enhancing biomass decay is the deterioration of COD removal efficiency due to the increase in the organic load of the bioreactor. This is evident in other sludge minimisation methods such as the disintegration of RAS by chlorination, and as such the effluent quality and commercial applicability of this technique is severely compromised (Wei et al., 2003). There is also a slight in increase in the organic content of the effluent during ozone treatment of RAS (Wei et al., 2003), yet overall organic removal efficiency is still satisfactory. On the other hand, 
studies have shown that the COD removal efficiency of aerobic bioreactors was unchanged (Chen et al., 2003; Chudoba et al., 1992) or improved (Goel and Noguera, 2006; Saby et al., 2003) by addition of an external anoxic or anaerobic tank (refer to Table 5 for comparison). A release of COD in the OSA tank of MBR-OSA was detected, especially at ORP of less than $+100 \mathrm{mV}$ (Saby et al., 2003). Nonetheless, this COD is consumed once sludge was returned to the MBR. This implies that most of the surplus COD generated in OSA is biodegradable, and has a minimal impact on overall COD removal efficiency. Furthermore, stable COD removal can be achieved as demonstrated by the pilotscale BIMINEX process treating real wastewater feed with a COD range of 150 to $900 \mathrm{mg} / \mathrm{L}$. It is interesting to explore cases where COD removal efficiency was improved by OSA. One explanation is that the cycle of fasting and feasting promotes substrate consumption (Saby et al., 2003). Saby et al. (2003) proposed that sludge that "fasted" in the anaerobic tank of MBR-OSA (Fig. 1b) consumes substrate faster as it replenished lost energy during "feasting" conditions in the aerobic reactor. Another explanation provided by Goel and Noguera (2006) in the case of EBPR SBRanaerobic SSR is the enrichment of fermenters and PAO, which degrades flocs and robustly converts substrate into storage polyhydroxyalkanoate (PHA), respectively. Chudoba et al. (1992) also noted an increase in the number of PAO in CAS-OSA, but did not see significant change in the COD removal efficiency of CAS. Nonetheless, there is evidence that anaerobic bacteria are responsible for the removal of surplus COD. An and Chen (2008) performed a mass balance analysis on closed batch reactors simulating OSA, and found that endogenous COD was consumed by denitrification, sulphate reduction, phosphate release, and methane production. Notably, 50\% of endogenous COD is used for methane production. The authors suggested that bacteria associated with these processes grow on the biofilm of the holding tank. Here, it is apparent that a greater understanding of the activities of various bacteria that are sustained in OSA and SSR will help explain the improvement in COD removal efficiency.

In contrast to other reports, Ye et al. (2008) emphasized that CAS-OSA had slightly lower COD removal efficiency (90-91\%) than CAS (93\%), and that COD removal efficiency was inversely proportional to the SRT of OSA (5.5-11.5 h). They explained that higher SRT improved the decomposition of biomass, which caused greater amounts of COD to be released. It is notable that the 
SRT of the OSA of Ye et al. (2008) was similar to that of Saby et al. (Saby et al., 2003)(10.6 h) and longer than that of Chudoba et al. (Chudoba et al., 1992) (3 h), yet those studies did not experience any deterioration of COD removal efficiency. Nonetheless, the variation in the COD removal efficiency of the OSA system and control aerobic system (2-3\%) is so small that it is probably negligible.

\section{[Table 5]}

\subsection{Effect on nitrogen removal}

Sludge cycling between aerobic and anoxic or anaerobic zones in the wastewater treatment loop creates an environment that is similar to the BNR process. Since previous studies used different measurements $\left(\mathrm{TN}\right.$ and $\left.\mathrm{NO}_{3}{ }^{-} \mathrm{N}\right)$ to assess nitrogen removal, it is difficult to make direct comparisons. Nonetheless, there is a consensus that nitrogen removal not negatively impacted by OSA and SSR. Ye et al (2008) reported that the TN removal efficiency of CAS-OSA (30\%) was similar to that of the control CAS (28-30\%) (Table 5). Saby et al. (2003) showed that $\mathrm{NO}_{3}{ }^{-}-\mathrm{N}$ in the effluent of MBR (34 $\mathrm{mg} / \mathrm{L}$ ) was higher than that of the MBR-OSA (11 to $25 \mathrm{mg} / \mathrm{L}$ ). The concentration of nitrate in the effluent of MBR-OSA was inversely proportional to the ORP of OSA $(+100 \mathrm{mV}$ to $-250 \mathrm{mV})$. This indicates that denitrification was enabled by OSA, and its efficiency was improved at more anaerobic conditions. Datta et al (2009) reported similar levels of $\mathrm{NH}_{3}-\mathrm{N}, \mathrm{NO}_{3}{ }^{-}-\mathrm{N}$ and $\mathrm{NO}_{2}{ }^{-} \mathrm{-N}$ in the effluents of control BNR SBR and BNR SBR-anaerobic SSR. More than $50 \%$ of $\mathrm{NO}_{3}{ }^{-}$was denitrified in the BNR SBR-anaerobic SSR, even though the anoxic stage of the SBR had a shortage of COD due to its consumption in the preceding anaerobic stage. It was speculated that this was due to the enrichment of denitrifying phosphate accumulating organisms (DNPAO), which are able to convert nitrate using their internal storage of PHA instead of external substrate. However, biomolecular testings were not performed in that study to confirm the hypothesis.

\subsection{Effect on phosphorous removal}

The EBPR process drives the uptake and release of orthophosphate by PAO through recycling sludge between aerobic and anaerobic phases, and separates phosphorous from wastewater through disposal of orthophosphate-rich sludge. The basic EBPR configuration involves an anaerobic tank followed by an aerobic tank, with a recirculation line in between (Zuthi et al., 2013). OSA harbours redox 
conditions that are similar to that of EBPR, and has been found to encourage the selection of PAO (Chudoba et al., 1992). However, another distinctive feature of OSA is the minimisation of sludge withdrawal, which may lead to the accumulation of phosphorous in the bioreactors.. Contradicting trends have been reported in literature regarding phosphorous removal in OSA. Chudoba et al (1992) showed that the $\mathrm{PO}_{4}^{-3}-\mathrm{P}$ removal efficiency of CAS-OSA (19-42\%) was higher than that of the control CAS (2-18\%), but the authors stressed that their findings might be misleading due to the dependence of phosphorous removal on the initial COD/P ratio. Nonetheless, they emphasized that CAS-OSA had a significantly greater population of PAO (60\% of the total bacterial community) than the control CAS (10\%). Ye at al. (2008) attributed the improvement of TP removal efficiency of CAS-OSA (48$58 \%)$ over control CAS (48.9\%) to higher substrate loading and the adsorption of phosphorous on biomass. Saby et al. (2003) reported that the $\mathrm{PO}_{4}{ }^{3-}-\mathrm{P}$ removal efficiency of an MBR-OSA (63\%) was similar to that of the control MBR (64\%) at ORP of $+100 \mathrm{mV}$. Nevertheless, removal efficiency of MBR-OSA decreased to $55 \%$ and $28 \%$ when ORP was adjusted to $-100 \mathrm{mV}$ and $-250 \mathrm{mV}$, respectively. This is in agreement with the conventional behaviour of PAO, i.e. assimilation of phosphate under aerobic or anoxic conditions (in the presence of substrate) and release of phosphate under anaerobic conditions. Here, it can be inferred that a possible drawback of maintaining lower ORP in OSA (which results in less sludge yield) is the heightened release of $\mathrm{PO}_{4}{ }^{3-}$. More investigations must be performed to clarify the effect of OSA on phosphate removal, and to find solutions (e.g. by modification of system configuration, sludge return ratio, or others) that will prevent the leakage of phosphate into the effluent.

There have been only a few studies that assessed the impact of anaerobic SSR on phosphorous removal. Datta et al. (2009) increased the $\mathrm{PO}_{4}{ }^{3-}-\mathrm{P}$ removal efficiency of a BNR SBR from $90 \%$ to 95\% by adding $30 \mathrm{~min}$ of aerobic stage in the SBR sequence (Mode 2 in Table 1), but applying the same modification to a BNR SBR-anaerobic SSR had no impact. Moreover, the $\mathrm{PO}_{4}{ }^{3-}-\mathrm{P}$ removal efficiency of the control SBR slightly increased when the initial COD/P ratio was increased from 9.1 to 21, whereas that of the SBR-anaerobic SSR remained the same. The implications of these findings require further investigation. Meanwhile, Goel and Noguera (2006) reported that EBPR SBR- 
anaerobic SSR had higher removal (97\%) than the control EBPR SBR (84\%) despite the surge of phosphate release in the anaerobic stage. Though available literatures suggest that phosphorous did not accumulate in the SBR even though sludge withdrawal was avoided, further studies must be performed to confirm how EBPR was sustained. In addition to EBPR, the precipitation of phosphorous as struvite in the anaerobic SSR might contribute to the loss of $\mathrm{PO}_{4}{ }^{3-} \mathrm{P}$ in the supernatant.

\section{Effect of sludge cycling on sludge characteristics}

\subsection{Microbial community}

Sludge cycling in different redox conditions is a unique condition that has high potential to create a distinct microbial population not only in the external tank, but also in the main aerobic reactor. Chen et al. (2003) and Saby et al. (2003) showed that MBR-OSA has 40-50\% more cells than MBR, but only $7-8 \%$ of these cells are respiring due to the periodic exposure of biomass to stressful conditions. Nonetheless, the inactivity of the majority of the cells did not affect organic matter removal efficiency (Saby et al., 2003). Bacteria found in OSA are similar to those in anaerobic digesters (Kim et al., 2012), therefore processes such as sulphate reduction and methane production occur within the OSA tank (An and Chen, 2008; Saby et al., 2003).As discussed in Section 4.5, wider microbial diversity that includes bacteria that typically grow under anaerobic conditions results from sludge recirculation. Among these bacteria are slow growers such as fermenters, PAO, and probably DNPAO, which also have roles in organic and nutrient removal from wastewater (Datta et al., 2009; Goel and Noguera, 2006). There is possibility that the domination of slow-growing bacteria induce sludge reduction. Identification and quantification of bacteria in OSA and reference systems is necessary to determine the change caused by OSA on the microbial profile of CAS.

\subsection{Sludge settleability and dewaterability}

Some studies emphasized that the implementation of OSA caused improvement to sludge settleability (refer to Table 5 for comparison). Higher sludge volume index (SVI, the volume in $\mathrm{mL}$ occupied by 1 $\mathrm{g}$ of activated sludge after $30 \mathrm{~min}$ of settling) implies poorer sludge settleability, and is usually associated with the domination of filamentous bacteria or greater concentration of EPS (Liu and Fang, 2003). Chudoba et al. (1992) reported filamentous bulking in both OSA and the control aerobic 
system, though OSA consistently had lower SVI. Ye et al. (2008) also observed that the SVI of the OSA system was generally lower than that of the control aerobic system. However, the value and stability of the SVI was easily affected by variations in SRT (5.5-11.5 h). The OSA system that was operated at the SRT of $7.6 \mathrm{~h}$ demonstrated the most consistent settleability. Different types of filamentous bacteria could grow at different SRT. Because bacterial characterization was not performed, it is difficult to explain how this particular condition resulted to better settleability i.e., lower SVI. Saby et al. (2003) observed that the SVI of the MBR-OSA system was palpably lower at $100 \mathrm{mV}$ (approximately $100 \mathrm{~mL}$ ) and $-250 \mathrm{mV}$ (less than $100 \mathrm{~mL}$ ) relative to that of the control MBR (175-360 mL). They speculated that enhanced cell lysis released microbial polymers that functioned as flocculant.

The dewaterability of OSA sludge is an important property that has not been investigated in detail. Sludge dewaterability is relevant in decreasing sludge volume, odour, bulking requirements, and leachate production (in the case of landfilling), and thereby in facilitating sludge handling and disposal (Tchobanoglus et al., 2003). It is affected by the amount and composition of EPS, which is the extremely hydrated portion of sludge. It was observed that thermal or oxidative treatment of sludge destroys EPS proteins and polysaccharides and reduces water retention (Neyens et al., 2004). Anaerobic digestion of sludge also decreases EPS concentration, but alters EPS composition such that it contains more proteins than polysaccharides. The result is the deterioration of sludge dewaterability, as indicated by an increase in its capillary suction time that denotes resistance to filtration (Houghton et al., 2000). Based on the trends observed in anaerobic digestion, it is possible that the extended exposure of sludge to anaerobic conditions during OSA could result to a sludge makeup that is difficult to dewater.

\section{Efficiency and cost}

Building on the information furnished in Table 1 and the preceding discussion on the OSA configurations, this section offers a clearer evaluation of the performance and cost of OSA and similar configurations against other sludge minimisation techniques. Average sludge reduction reported by independent studies (Supplementary Data S2) that performed thermal, thermochemical, ultrasonic, 
ozone, and chlorine treatment of WAS were $60 \%(n=2)$ (Camacho et al., 2005; Canales et al., 1994),

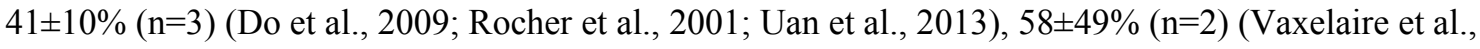
2008; Zhang et al., 2007), 85 $\pm 27 \%(\mathrm{n}=3$ ) (Ahn et al., 2002; Yasui et al., 1996; Yasui and Shibata, 1994), $59 \pm 10$ ( $\mathrm{n}=3$ ) sludge reduction, respectively. Meanwhile, the addition of metabolic uncouplers (TCS and various halogenated phenols) reduced sludge by an average of $63 \pm 23 \%(n=3)$ (Chen et al., 2000; Low and Chase, 1998; Yang et al., 2003). The average sludge reduction efficiency of OSA $(37 \pm 15, \mathrm{n}=5)$ (Chen et al., 2003; Chudoba et al., 1992; Saby et al., 2003; Wang et al., 2008; Ye et al., 2008) (Ye and Li, 2010)and anoxic or anaerobic SSR (39 $\pm 2, \mathrm{n}=3$ ) (Chon et al., 2011a; Chon et al., 2011b; Kim et al., 2012) are lower than that of ozonation, which has been applied commercially to minimise sludge (Yasui et al., 1996). They are within the range of those of thermochemical, ultrasonic, and chlorine treatment, as well as that of metabolic uncoupling addition. Because performances are similar, the advantage of OSA and SSR is their cost-effectiveness in terms of installation and maintenance. There is a dearth of information in peer-reviewed literature about the actual cost of either OSA or SSR. Only one study projected that the sludge treatment and disposal cost of CAS-OSA (10.2 million USD/year) can be $36.3 \%$ lower than that of CAS, and speculated that the savings will offset the capital cost of OSA installation (An and Chen, 2008). Moreover, unlike the other techniques, OSA or SSR does not release harmful chemical species (Section 2), and may improve organic removal efficiency and sludge settleability (Section 6).

\section{Future research priorities}

The major research gap in OSA and similar configurations that limits their widespread use is the lack of a thorough understanding of the mechanisms behind sludge minimisation. For instance, there is only speculation that bacterial predation influences sludge yield on OSA. There are strong arguments regarding the prevalence of biomass decay and EPS destruction, but findings suggest that various mechanisms simultaneously occur. Because of this issue, it is difficult to fine tune operating conditions such as SRT, ORP of the external tank, temperature, and others to further reduce sludge production. To improve the process, the interrelatedness and dominance of certain mechanisms should 
be elucidated. This effort necessitates an analysis of transformations in sludge biodiversity due to OSA, including various types of bacteria and higher organisms such as protozoa and metazoa.

As discussed in Section 3, the impact of certain designs requires further exploration. As an example, (Fig. 1e) the solids removal module of the Cannibal process eliminates the inert portion of the suspended solids. While this clearly reduces the amount of suspended solids, the effect of this procedure on sludge yield has not been assessed. There is also limited information on systems wherein the external sludge reduction unit has a sequence of redox conditions (e.g. the sludge interchange reactor of Cannibal process reported by Johnson et al. (2008) was an SBR) that exposes biomass to more complex growth conditions. Another aspect that needs to be further investigated is the impact of continuous vs. intermittent feeding to the external anaerobic tank on biomass growth. Comparison of available studies suggest that intermittent sludge loading results to higher SRT, but not necessarily greater sludge reduction relative to control CAS or SBR systems.

Due to its inclusion in the wastewater treatment line, OSA can impact treatment efficiency and sludge settleability. As discussed in Section 6.3, OSA has potential to deteriorate phosphorous removal due to the accumulation of phosphate-loaded sludge. Further study is needed to find solutions to this issue. It is also possible that OSA affects other sludge properties. For instance, the deterioration of odour and sludge dewaterability, which are important considerations in stabilization and eventual disposal of waste sludge, are usually associated with anaerobic digestion. In this context, more systematic studies on the effect of the OSA or SSR on the aforementioned sludge properties are necessary. This is relevant not only to increase their capacity to minimise sludge, but also to enhance wastewater treatment efficiency and handling of sludge before disposal.

Certain similarities of OSA tanks and digesters have been noted in this review. An interesting finding is that OSA and anaerobic digesters contains highly similar microbial communities, and therefore capabilities such as sulphate reduction and methane production. Biogas production and utilization in anaerobic digesters have been extensively researched, but the same cannot be said for OSA. It is worthwhile to explore the possibility of resource recovery from the anaerobic tank, which may be able 
to support the energy requirements of wastewater treatment. This will expand the cost effectiveness and commercial appeal of the OSA system.

The reduction in excess sludge production thus far achieved through sludge cycling is lower than sludge disintegration by advanced oxidation or other techniques (e.g., up to $55 \%$ in the case of MBROSA (Saby et al., 2003) vs. up to $100 \%$ in the case of ozonation (Yasui et al., 1996)). Therefore, a systematic cost-benefit analysis needs to be conducted to substantiate the notion that sludge cycling is a more cost effective option for sludge minimisation. The cost of installation, retrofitting, and operation of OSA and similar configurations should be calculated to determine potential savings related to sludge treatment and disposal, and then compared with other sludge minimisation technologies.

\section{Conclusion}

Alternately exposing sludge to growth-enhancing and growth-inhibiting conditions minimise sludge yield by impacting cellular metabolism, biomass decay, and sludge micro-biodiversity. Regardless of the configuration, the sludge reduction efficiency of sludge cycling is dependent on factors such as SRT, ORP, temperature, and sludge return ratio and loading mode (continuous or intermittent). This approach may have a positive impact on the COD and nutrient removal, and sludge settleability. Further investigations on the effect of sludge cycling on sludge dewaterability and odour are necessary. Comparative cost-benefit analyses with the alternative techniques are deemed indispensable to highlight the suitability of this process.

\section{Acknowledgment}

PhD Scholarship support to Galilee U. Semblante from the University of Wollongong is gratefully acknowledged.

\section{Reference}

[1] Ahn, K.H., Yeom, I.T., Park, K.Y., Maeng, S.K., Lee, Y., Song, K.G., Hwang, J.H. 2002. Reduction of sludge by ozone treatment and production of carbon source for denitrification. Water Sci Technol, 46, 121-125. 
[2] An, K., Chen, G. 2008. Chemical Oxygen Demand and the Mechanism of Excess Sludge Reduction in an Oxic-Settling-Anaerobic Activated Sludge Process. J Environ Eng, 134, 469477.

[3] Ayol, A., Filibeli, A., Sir, D., Kuzyaka, E. 2008. Aerobic and anaerobic bioprocessing of activated sludge: Floc disintegration by enzymes. J Environ Sci Health A, 43, 1528-1535.

[4] Camacho, P., Ginestet, P., Audic, J.M. 2005. Understanding the mechanisms of thermal disintegrating treatment in the reduction od sludge production. Water Sci Technol, 52, 235245.

[5] Canales, A., Parelleux, A., Rols, J. 1994. Decreased sludge production strategy for domestic wastewater treatment. Water Sci Technol, 30, 97-106.

[6] Chen, G.-H., An, K.-J., Saby, S., Brois, E., Djafer, M. 2003. Possible cause of excess sludge reduction in an oxic-settling-anaerobic activated sludge process (OSA process). Water Res, 37, 3855-3866.

[7] Chen, G.-H., Mo, H.-K., Liu, Y. 2002. Utilization of a metabolic uncoupler, 3,3' , , $4^{\prime}$,5tetrachlorosalicylanilide (TCS) to reduce sludge growth in activated sludge culture. Water Res, 36, 2077-2083.

[8] Chen, G.-H., Yip, W.-K., Mo, H.-K., Liu, Y. 2001a. Effect of sludge fasting/feasting on growth of activated sludge cultures. Water Res, 35, 1029-1037.

[9] Chen, G.H., Liu, Y. 1999. Modeling of energy spilling in substrate-sufficient cultures. J Environ Eng, 125, 508-513.

[10] Chen, G.H., Mo, H.K., Saby, S., Yip, W.K., Liu, Y. 2000. Minimization of activated sludge production by chemically stimulated energy spilling, Vol. 42, pp. 189-200.

[11] Chen, G.H., Saby, S., Djafer, M., Mo, H.K. 2001b. New approaches to minimize excess sludge in activated sludge systems. Water Sci Technol, 44, 203-208.

[12] Chon, D.-H., McNamara, R., Kim, H.-S., Park, C. 2011a. Investigating the mechanism of sludge reduction in activated sludge with an anaerobic side-stream reactor. Water Sci Technol, 63, 93-99.

[13] Chon, D.-H., Rome, M., Kim, Y.M., Park, K.Y., Park, C. 2011b. Investigation of the sludge reduction mechanism in the anaerobic side-stream reactor process using several control biological wastewater treatment processes. Water Res, 45, 6021-6029.

[14] Chu, L., Yan, S., Xing, X.-H., Sun, X., Jurcik, B. 2009. Progress and perspectives of sludge ozonation as a powerful pretreatment method for minimization of excess sludge production. Water Res, 43, 1811-1822.

[15] Chudoba, P., Morel, A., Capdeville, B. 1992. The case of both energetic uncoupling and metabolic selection of microorganisms in the OSA activated sludge system. Environ Technol, 13, 761-770.

[16] Clarke, B.O., Smith, S.R. 2011. Review of 'emerging' organic contaminants in biosolids and assessment of international research priorities for the agricultural use of biosolids. Environ Int, 37, 226-247.

[17] Coma, M., Rovira, S., Canals, J., Colprim, J. 2013. Minimization of sludge production by a sidestream reactor under anoxic conditions in a pilot plant. Bioresource Technol, 129, 229-235.

[18] Datta, T., Liu, Y., Goel, R. 2009. Evaluation of simultaneous nutrient removal and sludge reduction using laboratory scale sequencing batch reactors. Chemosphere, 76, 697-705.

[19] Do, K.-U., Banu, J.R., Chung, I.-J., Yeom, I.-T. 2009. Effect of thermochemical sludge pretreatment on sludge reduction and on performances of anoxic-aerobic membrane bioreactor treating low strength domestic wastewater. J Chem Technol Biot, 84, 1350-1355.

[20] Dubber, D., Gray, N.F. 2011. The effect of anoxia and anaerobia on ciliate community in biological nutrient removal systems using laboratory-scale sequencing batch reactors (SBRs). Water Res, 45, 2213-2226.

[21] Foladori, P., Andreottola, G., Ziglio, G. 2010. Sludge reduction technologies in wastewater treatment plants. IWA Publishing, London.

[22] Fytili, D., Zabaniotou, A. 2008. Utilization of sewage sludge in EU application of old and new methods-A review. Renew Sust Energ Rev, 12, 116-140.

[23] Ghyoot, W., Verstraete, W. 2000. Reduced sludge production in a two-stage membrane-assisted bioreactor. Water Res, 34, 205-215. 
[24] Goel, R., Noguera, D. 2006. Evaluation of Sludge Yield and Phosphorus Removal in a Cannibal Solids Reduction Process. J Environ Eng, 132, 1331-1337.

[25] Guo, W.-Q., Yang, S.-S., Xiang, W.-S., Wang, X.-J., Ren, N.-Q. 2013. Minimization of excess sludge production by in-situ activated sludge treatment processes - A comprehensive review. Biotechnol Adv.

[26] Hao, X.-D., Wang, Q.-L., Zhu, J.-Y., Van Loosdrecht, M.C.M. 2010. Microbiological Endogenous Processes in Biological Wastewater Treatment Systems. Crit Rev Env Sci Tec, 40, 239-265.

[27] Houghton, J.I., Quarmby, J., Stephenson, T. 2000. The Impact of Digestion on Sludge Dewaterability. Proc Saf Environ, 78, 153-159.

[28] Johnson, B.R. 2008. The use of ASM based models for the simulation of biological sludge reduction processes. Water Practice Technol, 3, 3-11.

[29] Kamiya, T., Hirotsuji, J. 1998. New combined system of biological process and intermittent ozonation for advanced wastewater treatment. Water Sci Technol, 38, 145-153.

[30] Khanal, S.K., Huang, J.-C. 2003. ORP-based oxygenation for sulfide control in anaerobic treatment of high-sulfate wastewater. Water Res, 37, 2053-2062.

[31] Kim, Y.M., Chon, D.-H., Kim, H.-S., Park, C. 2012. Investigation of bacterial community in activated sludge with an anaerobic side-stream reactor (ASSR) to decrease the generation of excess sludge. Water Res, 46, 4292-4300.

[32] Lee, N.M., Welander, T. 1996. Reducing sludge production in aerobic wastewater treatment through manipulation of the ecosystem. Water Res, 30, 1781-1790.

[33] Liu, Y. 1996. Bioenergetic interpretation on the S0X0 ratio in substrate-sufficient batch culture. Water Res, 30, 2766-2770.

[34] Liu, Y. 2003. Chemically reduced excess sludge production in the activated sludge process. Chemosphere, 50, 1-7.

[35] Liu, Y., Fang, H.H.P. 2003. Influences of Extracellular Polymeric Substances (EPS) on Flocculation, Settling, and Dewatering of Activated Sludge. Crit Rev Env Sci Tec, 33, 237273.

[36] Liu, Y., Tay, J.-H. 2001. Strategy for minimization of excess sludge production from the activated sludge process. Biotechnol Adv, 19, 97-107.

[37] Low, E.W., Chase, H.A. 1998. The use of chemical uncouplers for reducing biomass production during biodegradation. Water Sci Technol, 37, 399-402.

[38] Madoni, P. 2003. Protozoa as indicators of wastewater treatment efficiency. In: The handbook of water wans wastewater microbiology. Mara, D., Horan, N. (Eds.). Academic Press. London.

[39] Madoni, P. 1994. A sludge biotic index (SBI) for the evaluation of the biological performance of activated sludge plants based on the microfauna analysis. Water Res, 28, 67-75.

[40] Mahmood, T., Elliott, A. 2006. A review of secondary sludge reduction technologies for the pulp and paper industry. Water Res, 40, 2093-2112.

[41] Neyens, E., Baeyens, J. 2003. A review of thermal sludge pre-treatment processes to improve dewaterability. J Hazard Mater, 98, 51-67.

[42] Neyens, E., Baeyens, J., Dewil, R., De heyder, B. 2004. Advanced sludge treatment affects extracellular polymeric substances to improve activated sludge dewatering. J Hazard Mater, 106, 83-92.

[43] Novak, J.T., Chon, D.H., Curtis, B.A., Doyle, M. 2007. Biological solids reduction using the cannibal process. Water Environ Res, 79, 2380-2386.

[44] Novak, J.T., Khanthongthip, P., Doyle, M. 2011. Impact of Substrate Feed Patterns on Solids Reduction by the Cannibal Process. Proc Water Environ Fed, 2011, 660-673.

[45] Novak, J.T., Sadler, M.E., Murthy, S.N. 2003. Mechanisms of floc destruction during anaerobic and aerobic digestion and the effect on conditioning and dewatering of biosolids. Water Res, 37, 3136-3144.

[46] NWC. 2013. National performance report 2011-12: Urban water utilities. Australian Government - National Water Commission. ISBN 978-1-922136-15-2.

[47] Park, C., Abu-Orf, M.M., Novak, J.T. 2006. The Digestibility of Waste Activated Sludges. Water Environ Res, 78, 59-68. 
[48] Pilli, S., Bhunia, P., Yan, S., LeBlanc, R.J., Tyagi, R.D., Surampalli, R.Y. 2011. Ultrasonic pretreatment of sludge: A review. Ultrason Sonochem, 18, 1-18.

[49] Quan, F., Anfeng, Y., Libing, C., Hongzhang, C., Xing, X.-H. 2012. Mechanistic study of on-site sludge reduction in a baffled bioreactor consisting of three series of alternating aerobic and anaerobic compartments. Biochem Eng J, 67, 45-51.

[50] Ratsak, C., Verkuijlen, J. 2006. Sludge reduction by predatory activity of aquatic oligochaetes in wastewater treatment plants: science or fiction? A review. In: Aquatic Oligochaete Biology IX. Verdonschot, P.M., Wang, H., Pinder, A., Nijboer, R. (Eds.). Springer Netherlands.

[51] Rocher, M., Roux, G., Goma, G., Pilas Begue, A., Louvel, L., Rols, J.L. 2001. Excess sludge reduction in activated sludge processes by integrating biomass alkaline heat treatment. Water Sci Technol, 44, 437-444.

[52] Rosenberger, S., Witzig, R., Manz, W., Szewzyk, U., Kraume, M. 2000. Operation of different membrane bioreactors: Experimental results and physiological state of the micro-organisms. Water Sci Technol, 41, 269-277.

[53] Saby, S., Djafer, M., Chen, G.H. 2003. Effect of low ORP in anoxic sludge zone on excess sludge production in oxic-settling-anoxic activated sludge process. Water Res, 37, 11-20.

[54] Saby, S., Djafer, M., Chen, G.H. 2002. Feasibility of using a chlorination step to reduce excess sludge in activated sludge process. Water Res, 36, 656-666.

[55] Sheridan, J., Curtis, B.A. 2004. Revolutionary technology cuts biosolids production and costs. Pollut Eng, 36, 44-47.

[56] Sperling, M.V. 2007. Activated Sludge and Aerobic Biofilm Reactors. IWA Publishing, London.

[57] Sun, L., Randall, C.W., Novak, J.T. 2010. The Influence of Sludge Interchange Times on the Oxic-Settling-Anoxic Process. Water Environ Res, 82, 519-23.

[58] Takdastan, A., Eslami, A. 2013. Application of energy spilling mechanism by para-nitrophenol in biological excess sludge reduction in batch-activated sludge reactor. Int J Energy Environ Eng, 4, 1-7.

[59] Tchobanoglus, G., Burton, F., Stensel, H. 2003. Wastewater engineering: Treatment and reuse. American Water Works Association, New York.

[60] Troiani, C., Eusebi, A.L., Battistoni, P. 2011. Excess sludge reduction by biological way: From experimental experience to a real full scale application. Bioresource Technol, 102, 1035210358.

[61] Uan, D.K., Yeom, I.T., Arulazhagan, P., Rajesh Banu, J. 2013. Effects of sludge pretreatment on sludge reduction in a lab-scale anaerobic/anoxic/oxic system treating domestic wastewater. Int J Environ Sci Technol, 10, 495-502.

[62] Vaxelaire, S., Gonze, E., Merlin, G., Gonthier, Y. 2008. Reduction by sonication of excess sludge production in a conventional activated sludge system: continuous flow and lab-scale reactorj. Environ Technol, 29, 1307-1320.

[63] Wang, J., Zhao, Q., Jin, W., Lin, J. 2008. Mechanism on minimization of excess sludge in oxicsettling-anaerobic (OSA) process. Front Environ Sci Eng China, 2, 36-43.

[64] Wei, Y., Van Houten, R.T., Borger, A.R., Eikelboom, D.H., Fan, Y. 2003. Minimization of excess sludge production for biological wastewater treatment. Water Res, 37, 4453-4467.

[65] Westgarth, W., Sulzer, F., Okun, D. 1964. Anaerobiosis in the activated sludge process. 2nd IAWPRC Conf. pp. 43-55.

[66] Yang, S.-S., Guo, W.-Q., Zhou, X.-J., Meng, Z.-H., Liu, B., Ren, N.-Q. 2011. Optimization of operating parameters for sludge process reduction under alternating aerobic/oxygen-limited conditions by response surface methodology. Bioresource Technol, 102, 9843-9851.

[67] Yang, X.-F., Xie, M.-L., Liu, Y. 2003. Metabolic uncouplers reduce excess sludge production in an activated sludge process. Proc Biochem, 38, 1373-1377.

[68] Yasui, H., Nakamura, K., Sakuma, S., Iwasaki, M., Sakai, Y. 1996. A full-scale operation of a novel activated sludge process without excess sludge production. Water Sci Technol, 34, 395404.

[69] Yasui, H., Shibata, M. 1994. An innovative approach to reduce excess sludge production in the activated sludge process. Water Sci Technol, 30, 11-20. 
[70] Ye, F.-X., Zhu, R.-F., Li, Y. 2008. Effect of sludge retention time in sludge holding tank on excess sludge production in the oxic-settling-anoxic (OSA) activated sludge process. J Chem Technol Biot, 83, 109-114.

[71] Ye, F., Li, Y. 2010. Oxic-settling-anoxic (OSA) process combined with 3,3' , , $4^{\prime}$,5tetrachlorosalicylanilide (TCS) to reduce excess sludge production in the activated sludge system. Biochem Eng J, 49, 229-234.

[72] Zhang, G., Zhang, P., Yang, J., Chen, Y. 2007. Ultrasonic reduction of excess sludge from the activated sludge system. J Hazard Mater, 145, 515-519.

[73] Zuthi, M.F.R., Guo, W.S., Ngo, H.H., Nghiem, L.D., Hai, F.I. 2013. Enhanced biological phosphorus removal and its modeling for the activated sludge and membrane bioreactor processes. Bioresource Technol, 139, 363-374. 


\section{List of figures}

Figure 1 Various configurations: CAS-OSA that routes $80-100 \%$ of the thickened sludge from the settling tank to the anaerobic or anoxic holding tank (a); MBR-OSA (b); SBR-anaerobic SSR that treats thickened sludge in the SSR prior to its return to the SBR during the FILL stage (c);

BIMINEX ${ }^{\circledR}$, which comprises a UCT with an anoxic SSR, that treats a part or all of the thickened return activated sludge (d); full-scale Cannibal ${ }^{\circledR}$ with solids removal module (e)

Figure 2 The sludge growth cycle: the proposed sludge minimization mechanisms in OSA and similar configurations due to alternate exposure to aerobic and anaerobic/anoxic conditions could occur at various locations in the cycle as marked by

Figure 3 Catabolism and anabolism are linked by the phosphoryrlation/dephosphorylation of ATP (a). Energy uncoupling occurs when energy levels between catabolism and anabolism are unequal, which leads to prevention of cell growth (adapted from (Chudoba et al., 1992)). Cyclic depletion (fasting) and replenishment (feasting) of ATP stores result to energy uncoupling (b).

Figure 4 Sludge yield at various SRT of OSA and similar configurations. Data source: (Chen et al., 2003; Chon et al., 2011a; Chudoba et al., 1992; Datta et al., 2009; Novak et al., 2007; Saby et al., 2003) 
(a) CAS-OSA

(b) MBR-OSA
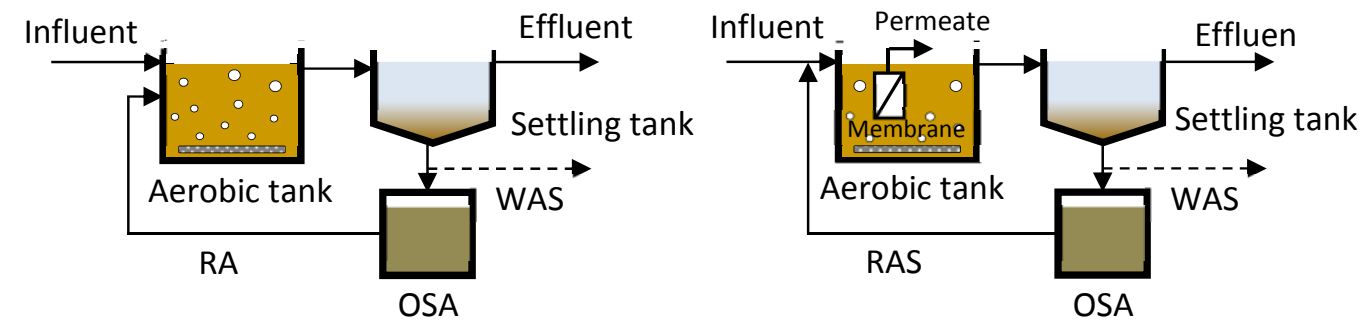

(c) SBR-anaerobic SSR

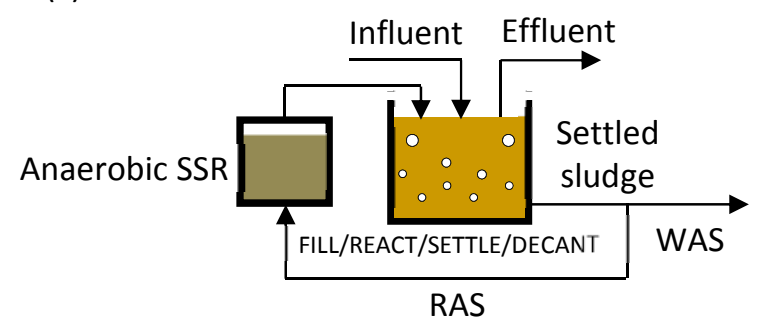

(d) Cannibal ${ }^{\circledR}$

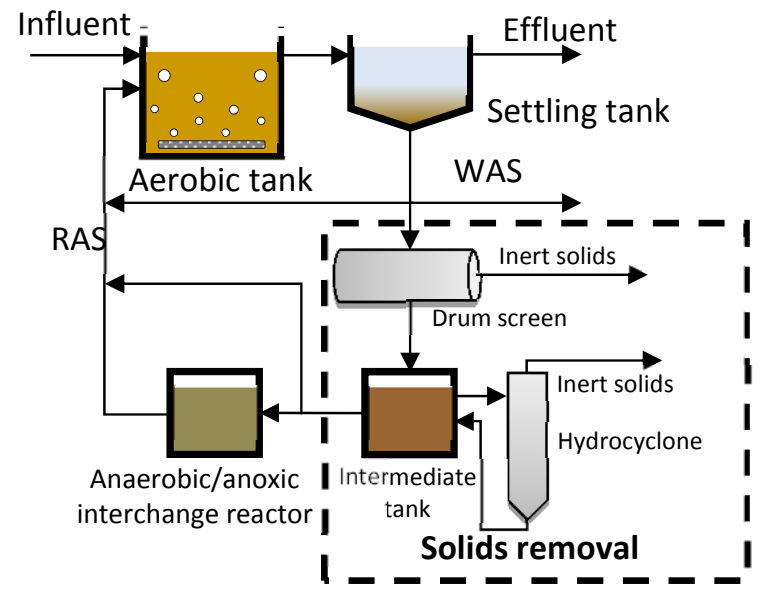

(e)

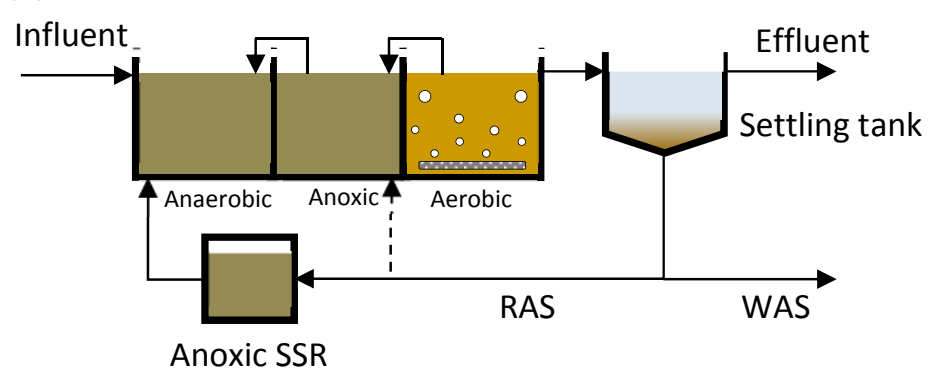

Figure 1 


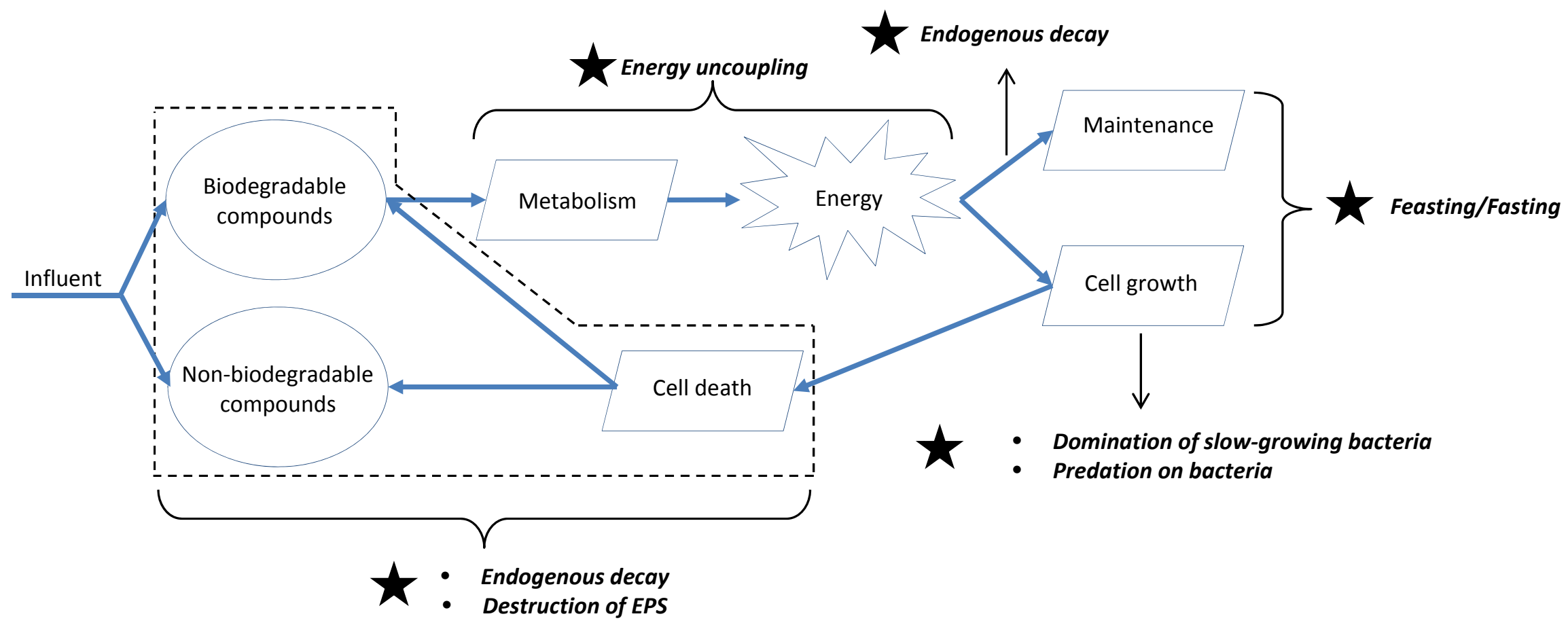

Figure 2 
(a) Relationship of catabolism and anabolism

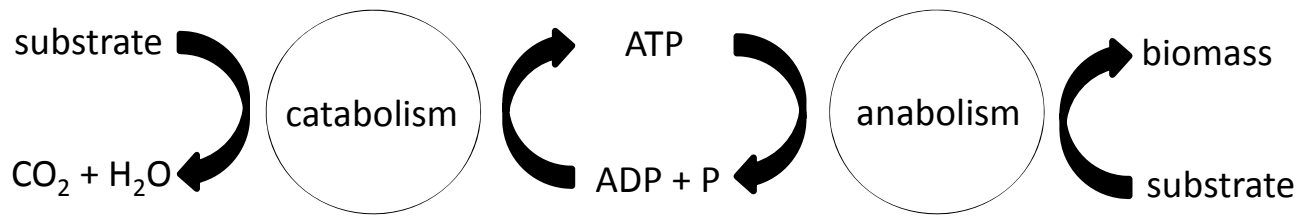

(b) Sludge fasting/feasting

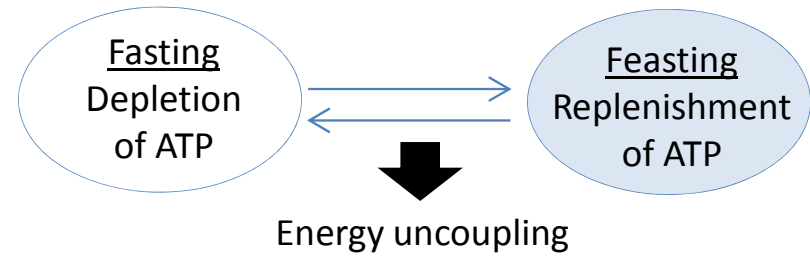

Figure 3 


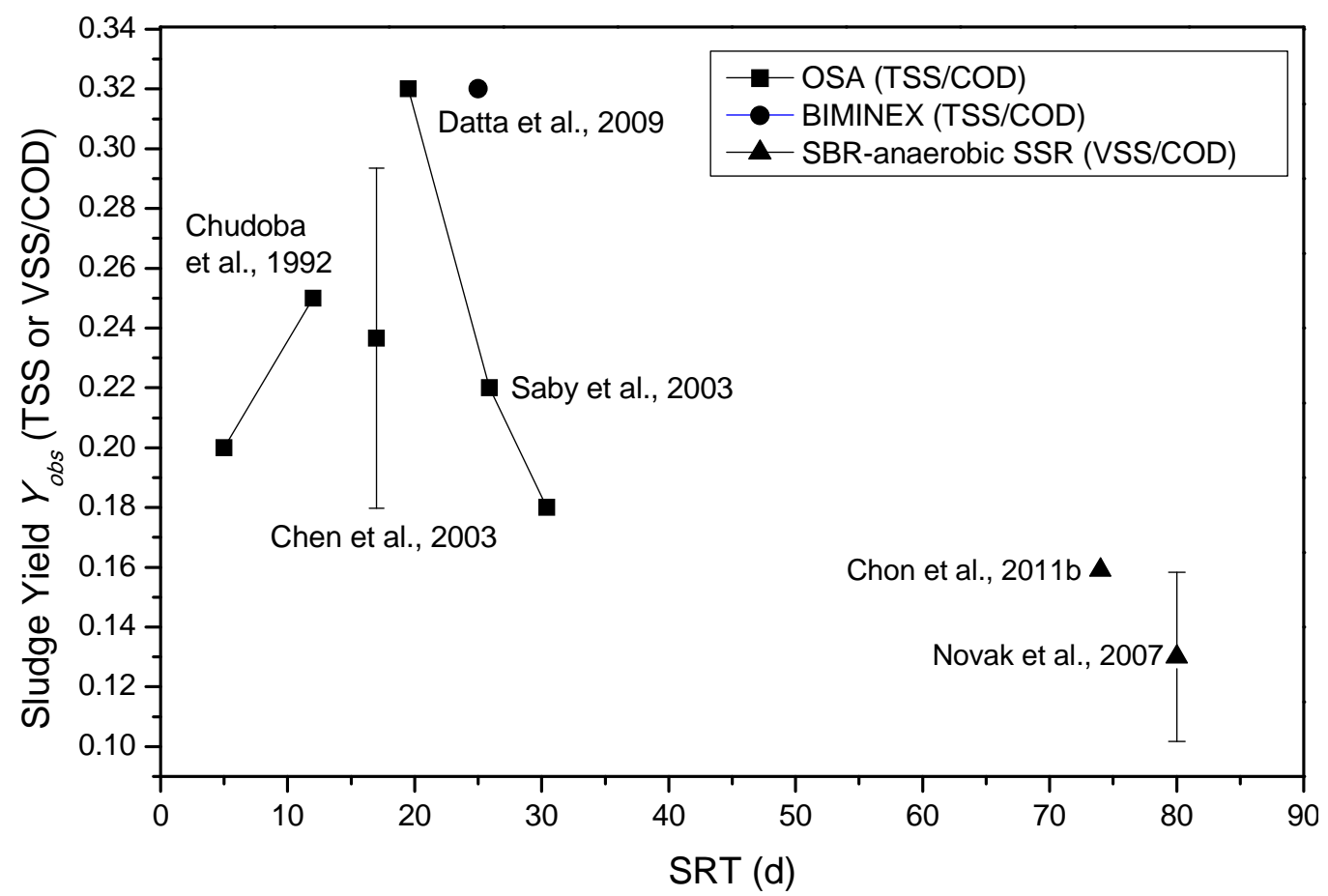

Figure 4 


\section{LIST OF TABLES}

Table 1 Advantages and disadvantages of representative sludge minimisation techniques

Sludge minimization technique

1. Optimization of operation parameters (SRT and DO)

\section{Advantages}

Ease of

implementation;

improves

settleability

Improves

dewaterability;

inactivates

pathogens; reduces

sludge viscosity

Improves

Thermochemical dewaterability;

treatment

inactivates

pathogens

2. Sludge disintegration

\begin{tabular}{ll}
\hline & $\begin{array}{l}\text { Reduces foaming; } \\
\text { Ultrasonication }\end{array}$ \\
improves \\
settleability
\end{tabular}

High sludge
reduction

Ozonation

\begin{tabular}{ll} 
& $\begin{array}{l}\text { improves } \\
\text { settleability }\end{array}$ \\
\hline Chlorination & $\begin{array}{l}\text { Less expensive than } \\
\text { ozonation }\end{array}$
\end{tabular}

Disadvantages

High aeration

demand; minor

sludge reduction

Odour formation;

high energy

consumption

Odour formation;

high energy

consumption

Requires expensive

equipment; high

energy

consumption; poor

dewaterability

Requires expensive

equipment; high

energy

consumption; forms

toxic by-products

Worsens

settleability and

COD removal;

forms toxic by-

products

Uses expensive and

potentially

hazardous

3. Metabolic uncoupler

Ease of

implementation

chemicals; poor

settleability and dewaterability

Lower capital and

4. Aerobic/anaerobic/anoxic cycling operating cost;

improves

settleability
Less sludge reduction than the disintegration methods; process knowledge gaps
Selected references

(Foladori et al., 2010; Wei et al., 2003)

(Foladori et al., 2010; Neyens and

Baeyens, 2003)

(Foladori et al., 2010; Neyens and Baeyens, 2003)

(Zhang et al., 2007)

(Chu et al., 2009; Foladori et al., 2010; Mahmood and Elliott, 2006)

(Saby et al., 2002;

Wei et al., 2003)

(Clarke and Smith, 2011; Foladori et al., 2010)

(Chen et al., 2003;

Foladori et al., 2010; Goel and Noguera, 2006) 
Table 2 Sludge yields of aerobic reactors (CAS, MBR, and SBR) coupled with OSA and anaerobic SSR

\begin{tabular}{|c|c|c|c|c|c|c|c|}
\hline Configuration & $\begin{array}{c}\text { Description } \\
\text { of sludge } \\
\text { loading } \\
\text { scheme to } \\
\text { OSA/SSR }\end{array}$ & $\begin{array}{l}\text { Control } \\
\text { system }\end{array}$ & $\begin{array}{c}\text { SRT } \\
\text { (d) }\end{array}$ & $\begin{array}{l}\text { ORP } \\
(\mathrm{mV})\end{array}$ & $\begin{array}{c}\text { Sludge } \\
\text { reduction } \\
(\%)\end{array}$ & $Y_{o b s}$ & Reference \\
\hline 1.CAS-OSA & $\begin{array}{l}\text { Continuous, } \\
\text { HRT }=3 \mathrm{~h}\end{array}$ & $\begin{array}{l}\text { CAS } \\
\text { (Fig. } \\
\text { la) }\end{array}$ & $5-12$ & -250 & $40-50$ & $\begin{array}{l}0.2-0.29 \\
\text { (TSS/COD) }\end{array}$ & $\begin{array}{l}\text { (Chudoba } \\
\text { et al., } \\
1992)\end{array}$ \\
\hline 2. MBR-OSA & Continuous & $\begin{array}{l}\text { MBR } \\
\text { only } \\
\text { (no } \\
\text { settling } \\
\text { tank) }\end{array}$ & $\begin{array}{l}19.5- \\
30.4\end{array}$ & $\begin{array}{l}-250 \text { to } \\
100\end{array}$ & $23.4-51.1$ & $\begin{array}{l}0.18-0.32 \\
\text { (MLSS/COD) }\end{array}$ & $\begin{array}{l}\text { (Saby et } \\
\text { al., 2003) }\end{array}$ \\
\hline $\begin{array}{l}\text { 3.SBR- } \\
\text { anaerobic SSR }\end{array}$ & $\begin{array}{l}\text { Sludge } \\
\text { settled from } \\
10 \% \text { of } \\
\text { mixed } \\
\text { liquor was } \\
\text { loaded to } \\
\text { the SSR } \\
\text { once a day }\end{array}$ & $\begin{array}{l}\text { SBR } \\
\text { with no } \\
\text { sludge } \\
\text { wastage }\end{array}$ & 74 & $\begin{array}{l}\text { Not } \\
\text { reported }\end{array}$ & $15 \%$ & $\begin{array}{l}0.16 \\
\text { (VSS/COD) }\end{array}$ & $\begin{array}{l}\text { (Chon et } \\
\text { al., } \\
\text { 2011b) }\end{array}$ \\
\hline $\begin{array}{l}\text { 4. SBR- } \\
\text { anaerobic SSR }\end{array}$ & $\begin{array}{l}4-7 \% \text { of the } \\
\text { settled } \\
\text { sludge in } \\
\text { SBR was } \\
\text { loaded to } \\
\text { the SSR } \\
\text { once per } \\
\text { day }\end{array}$ & $\begin{array}{l}\text { SBR } \\
\text { with no } \\
\text { sludge } \\
\text { wastage }\end{array}$ & $\begin{array}{l}80- \\
100\end{array}$ & $\begin{array}{l}\text { Not } \\
\text { reported }\end{array}$ & $20-45$ & $\begin{array}{l}0.11-0.15 \\
\text { (VSS/COD) }\end{array}$ & $\begin{array}{l}\text { (Novak et } \\
\text { al., 2007) }\end{array}$ \\
\hline
\end{tabular}


Table 3 Sludge yield of aerobic- $v s$. BNR-SBR coupled with anaerobic SSR

\begin{tabular}{llll}
\hline Configuration & \multicolumn{1}{c}{$\begin{array}{c}\text { SBR operation } \\
\text { (FILL/REACT/SETTLE/DECANT, h) }\end{array}$} & \multicolumn{1}{c}{$\boldsymbol{Y}_{\text {obs }}$} & Reference \\
\hline $\begin{array}{l}\text { SBR- } \\
\text { anaerobic SSR }\end{array}$ & $0.17 / 5$ (aerobic) $/ 1 / 0.17$ & $0.16 \mathrm{VSS} / \mathrm{COD}$ & (Chon et al., 2011a) \\
\hline $\begin{array}{l}\text { SBR- } \\
\text { anaerobic SSR }\end{array}$ & $0.17 / 5($ aerobic) $/ 1 / 0.17$ & $0.11-0.17 \mathrm{VSS} / \mathrm{COD}$ & (Chon et al., 2011a) \\
\hline $\begin{array}{l}\text { SBR- } \\
\text { anaerobic SSR }\end{array}$ & $0.17 / 5($ aerobic) $/ 1 / 0.17$ & $0.16 \mathrm{VSS} / \mathrm{COD}$ & (Kim et al., 2012) \\
\hline $\begin{array}{l}\text { EBPR SBR- } \\
\text { anaerobic SSR }\end{array}$ & 2 (aerobic) / 3 (aerobic) $/ 0.92 / 0.08$ & $0.16 \mathrm{TSS} / \mathrm{COD}$ & $\begin{array}{l}\text { (Goel and Noguera, } \\
\text { 2006) }\end{array}$ \\
\hline & $\begin{array}{l}\text { Mode } 1: 1.5(\text { anaerobic) } / 2.5 \text { (aerobic)-1.5 } \\
\text { (anoxic) } / 0.5 / 0.5\end{array}$ & \\
$\begin{array}{l}\text { BNR SBR- } \\
\text { anaerobic SSR }\end{array}$ & $\begin{array}{l}\text { Mode 2: } 1.25 \text { (anaerobic) } / 2.25 \text { (aerobic) }- \\
1.5 \text { (anoxic) - 0.5 (aerobic) } / 0.5\end{array}$ & $0.17 \mathrm{TSS} / \mathrm{COD}$ & (Datta et al., 2009) \\
\hline & & & \\
\hline
\end{tabular}


Table 4 Sludge yield of systems at different ORP and SRT

\begin{tabular}{|c|c|c|c|c|}
\hline Configuration & ORP (mV) & SRT (days) & $\mathbf{Y}_{\text {obs }}$ & Reference \\
\hline CAS-OSA & -250 & 5 & 0.29 (TSS/COD) & $\begin{array}{c}\text { (Chudoba et al., } \\
\text { 1992) }\end{array}$ \\
\hline CAS-OSA & -250 & 12 & $0.2(\mathrm{TSS} / \mathrm{COD})$ & $\begin{array}{c}\text { (Chudoba et al., } \\
1992)\end{array}$ \\
\hline CAS-OSA & -250 & Not reported & $\begin{array}{c}0.49 \\
\text { (MLSS/COD) }\end{array}$ & $\begin{array}{c}\text { (Wang et al., } \\
\text { 2008) }\end{array}$ \\
\hline MBR-OSA & -250 & 30.4 & $\begin{array}{c}0.18 \\
\text { (MLSS/COD) }\end{array}$ & (Saby et al., 2003) \\
\hline MBR-OSA & -250 & 17 & 0.3 (MLSS/COD) & $\begin{array}{c}\text { (Chen et al., } \\
\text { 2003) }\end{array}$ \\
\hline BIMINEX & -150 & 26.2 & $0.327(\mathrm{VSS} / \mathrm{COD})$ & $\begin{array}{c}\text { (Coma et al., } \\
\text { 2013) }\end{array}$ \\
\hline MBR-OSA & -100 & 25.9 & $\begin{array}{c}0.22 \\
\text { (MLSS/COD) }\end{array}$ & (Saby et al., 2003) \\
\hline MBR-OSA & -100 & 17 & $0.22(\mathrm{TSS} / \mathrm{COD})$ & $\begin{array}{c}\text { (Chen et al., } \\
2003)\end{array}$ \\
\hline MBR-OSA & +100 & 19.5 & $\begin{array}{c}0.32 \\
\text { (MLSS/COD) }\end{array}$ & (Saby et al., 2003) \\
\hline MBR-OSA & +100 & 17 & 0.19 (TSS/COD) & $\begin{array}{c}\text { (Chen et al., } \\
\text { 2003) }\end{array}$ \\
\hline
\end{tabular}


Table 5 Effect of OSA and SSR on wastewater treatment efficiency (COD, phosphorous, and nitrogen removal) and sludge settleability

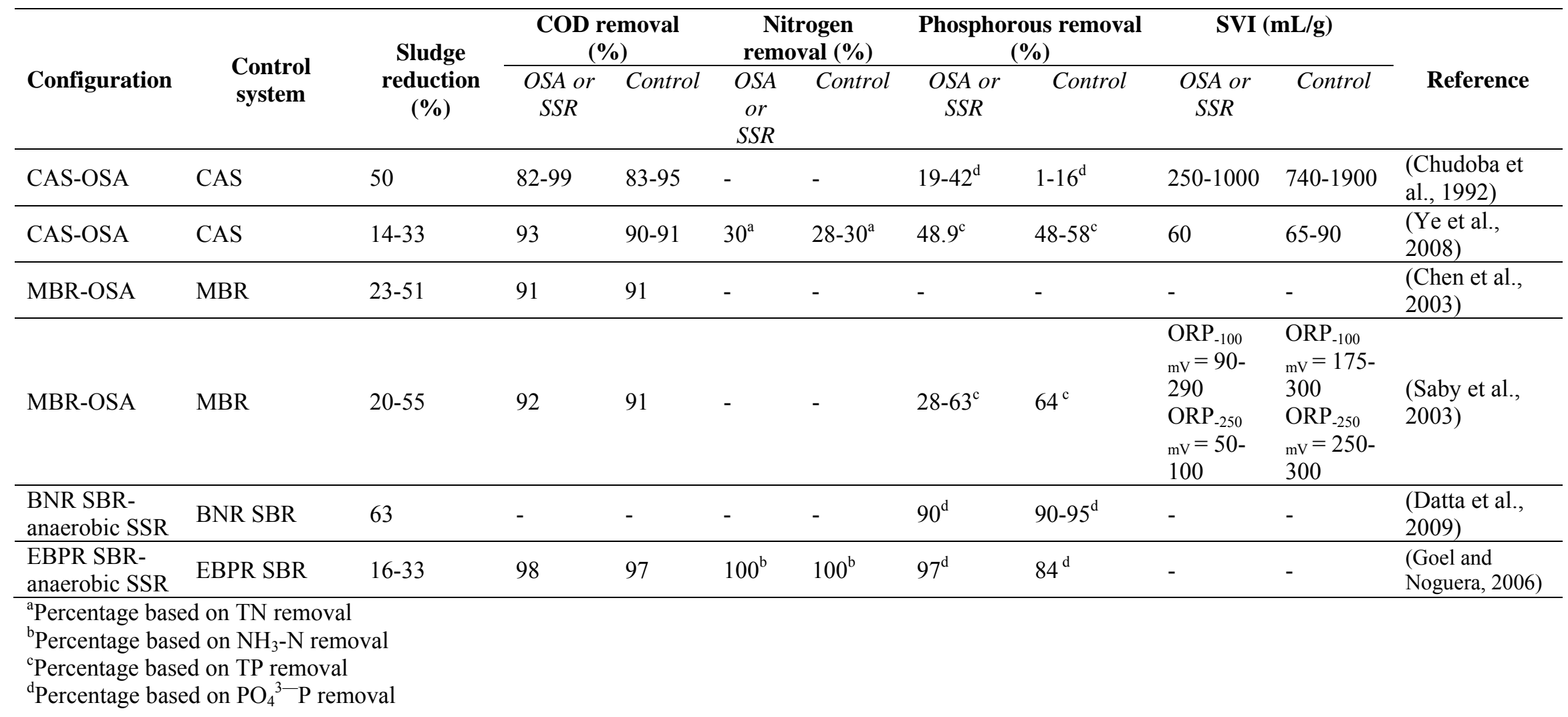




\title{
Sludge cycling between aerobic, anoxic and anaerobic regimes to reduce sludge production during wastewater treatment: performance, mechanisms, and implications
}

\author{
Supplementary Data submitted to \\ Bioresource Technology \\ Jan 2014 \\ Galilee U. Semblante ${ }^{\mathrm{a}}$, Faisal I. Hai ${ }^{\mathrm{a} *}$, Huu H. Ngo ${ }^{\mathrm{b}}$, Wenshan Guo ${ }^{\mathrm{b}}$, Sheng-Jie You ${ }^{\mathrm{c}}$, William E. \\ Price $^{\mathrm{d}}$, and Long D. Nghiem ${ }^{\mathrm{a}}$

\footnotetext{
University of Wollongong, Wollongong, NSW 2522, Australia

${ }^{\mathrm{b}}$ Centre for Technology in Water and Wastewater, School of Civil and Environmental Engineering, University of Technology Sydney, Sydney, Broadway, NSW 2007, Australia

${ }^{c}$ Department of Bioenvironmental Engineering and R\&D Centre for Membrane Technology, Chung Yuan Christian University, Chungli 320, Taiwan

d Strategic Water Infrastructure Laboratory, School of Chemistry, University of Wollongong,
} \\ a Strategic Water Infrastructure Laboratory, School of Civil, Mining and Environmental Engineering, \\ Wollongong, NSW 2522, Australia \\ * Corresponding author:
}

Email: faisal@uow.edu.au, Ph +61 242213054 

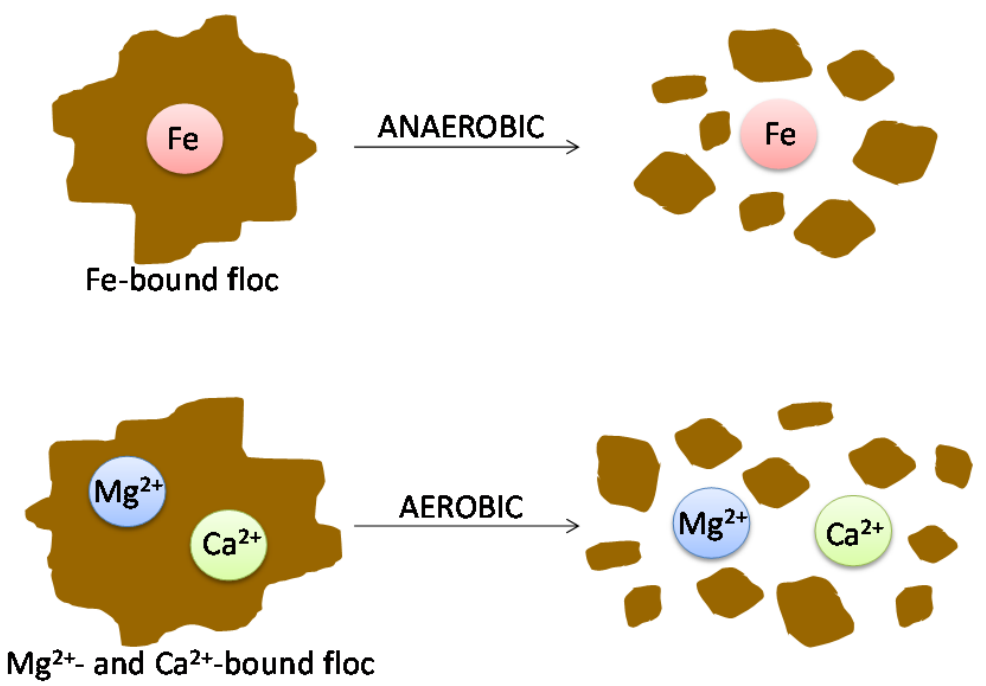

Figure S1 EPS destruction - The destruction of Fe-bound floc at anaerobic conditions and $\mathrm{Mg}^{2+}$ - and $\mathrm{Ca}^{2+}$-bound floc at aerobic conditions improves biomass decay 


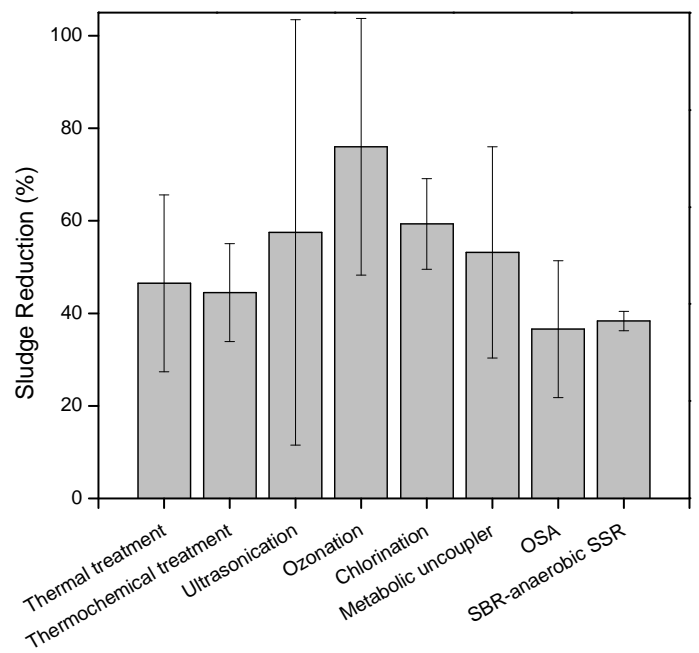

\section{Figure S2}

Figure S2 Sludge reduction by various sludge minimisation technologies. Error bars indicate

variation in data compiled from different independent studies [No. of data: Thermal treatment (2), thermochemical treatment (3), ultrasonication (2), ozonation (3), chlorination (3), metabolic uncoupler (3), OSA (5), SBR-anaerobic SSR (3). Data Source: (Ahn et al., 2002; Camacho et al., 2005; Canales et al., 1994; Chen et al., 2003; Chen et al., 2002; Chen et al., 2001; Chon et al., 2011a; Chon et al., 2011b; Chudoba et al., 1992; Do et al., 2009; Kamiya \& Hirotsuji, 1998; Kim et al., 2012; Low \& Chase, 1998; Rocher et al., 2001; Saby et al., 2003; Saby et al., 2002; Takdastan \& Eslami, 2013; Uan et al., 2013; Vaxelaire et al., 2008; Wang et al., 2008; Yang et al., 2003; Yasui et al., 1996; Ye et al., 2008; Zhang et al., 2007) 
